\title{
Semi-kinematic geodetic reference frame based on the ITRF2014 for Malaysia
}

DOI: https://doi.org/10.1515/jogs-2020-0108

Received April 19, 2020; accepted October 10, 2020

Abstract: Malaysia is located at the stable part of the tectonic Sundaland platelet in SE Asia. The platelet is surrounded in almost every direction by tectonically active convergent boundaries, at which the Philippine Sea, the Australian and the Indian Plates are subducting respectively from the East, South and West.The current Malaysia geodetic reference frame called MGRF2000 is a static reference frame and hence did not incorporate the effects of plate motion and the ensuing deformation from (megathrust) earthquakes. To prevent degradation of Continuously Operating Reference Station (CORS) coordinates, a new time-dependent national reference frame was developed. Taking advantage of the availability of the GNSS data of the CORS network in Malaysia, notably the Malaysia Active GPS System (MASS) and Malaysia Real-Time Kinematic GNSS Network (MyRTKnet), a more accurate and robust Malaysian geodetic reference frame was determined, fully aligned and compatible with ITRF2014. The cumulative solution obtained from stacking Malaysian CORS position time series formed the basis of the new MGRF2020 realization. It consists of $100+$ station positions at epoch 2020.0, station velocities and Post-Seismic Deformation (PSD) parametric models for stations subjected to major earthquakes. The (1999-2018) position time series exhibit Weighted Mean Root Square (WRMS) values of 3.0, 3.2 and

M. Azhari, G. Azman, R. Sohaime, M.Y. Yunus, M.J. Irwan, C.A. Asyran: Department of Survey and Mapping Malaysia, Jalan Sultan Yahya Petra, 50578 Kuala Lumpur, Malaysia

Z. Altamimi: Institut National de Information Geographique et Forestiere (IGN), LAREG, Batiment Larmarck A, 5 rue Thomas Mann, Case courier 7011, 75205 Paris Cedex 13, France

*Corresponding Author: M. Kadir: Info-Geomatik, 72 Jalan Pendidikan 4, 81300 Skudai, Taman Universiti, Johor, Malaysia, E-mail: igeom2006@gmail.com

N. Soeb, A. Fahmi: Info-Geomatik, 72 Jalan Pendidikan 4, 81300 Skudai, Taman Universiti, Johor, Malaysia

W.J.F Simons: Astrodynamics and Space Missions, Space Engineering Department, Faculty of Aerospace Engineering, Delft University of Technology, Netherlands

A. Saiful: Faculty of Architecture, Planning and Surveying, Universiti Teknologi MARA, 40450 Shah Alam, Selangor, Malaysia
$7.6 \mathrm{~mm}$ in respectively the East, North and Vertical components. A new semi-kinematic geodetic datum (GDM2020) for Malaysia, useable for GIS, mapping and cadastre applications is proposed to replace the existing static datum (GDM2000). A transformation suite to convert the spatial databases from GDM2000 to GDM2020 was also developed.

Keywords: Geodetic reference frame; semi-kinematic; time series analysis; ITRF2014

\section{Introduction}

The current Malaysia geodetic datum is known as the Geocentric Datum for Malaysia 2000 (GDM2000), and was adopted by the Department of Surveying and Mapping Malaysia (DSMM) on 26th August 2003. Prior to GDM2000, the geodetic infrastructure in Peninsular Malaysia and East Malaysia was based on separate classical non-geocentric geodetic datums known as Malayan Revised Triangulation 1948 (MRT48) and Borneo Triangulation 1968 (BT68), respectively (Kadir et al., 2003). The Malaysian Geodetic Reference Frame 2000 (MGRF2000) served as the foundation for GDM2000 and was developed using the first four years of GPS data of 17 stations from the Malaysia Active GPS System (MASS), i.e. the first network of Continuously Operating Reference Stations (CORS) in Malaysia. The MGRF2000 was aligned with the International Terrestrial Reference Frame 2000 (ITRF2000) at epoch 2000.0, in origin, scale and orientation (Table 1) (Kadir et al., 2003).

The main purpose of introducing GDM2000 was to replace the classical non-geocentric MRT48 and BT68 datums and to allow for compatibility and integration with

Table 1. GDM2000 defining parameters

\begin{tabular}{ll}
\hline International Terrestrial Reference Frame & ITRF2000 origin, scale and orientation \\
National Geodetic Reference Frame & MGRF2000 \\
Reference Epoch & 2000.0 \\
Reference Ellipsoid & GRS80 Ellipsoid \\
Height System & MyGeoid(2003) \\
\hline
\end{tabular}


modern space-based positioning technologies with centimetre accuracy. The adoption of GDM2000 has facilitated the integration of spatial datasets and consequently provide better data sharing, handling and management of the related datasets. Nevertheless, the GDM2000 datum was defined as a static traditional geodetic datum where all sites of the MGRF2000 are assumed to have coordinates which are fixed and not change with time. This is an incorrect assumption since the surface of the earth is constantly changing because of the tectonic plate motions. However, if all points are located on the same (robust) tectonic plate, relative positioning with respect to any reference site will not be affected by the absolute motion of the plate.

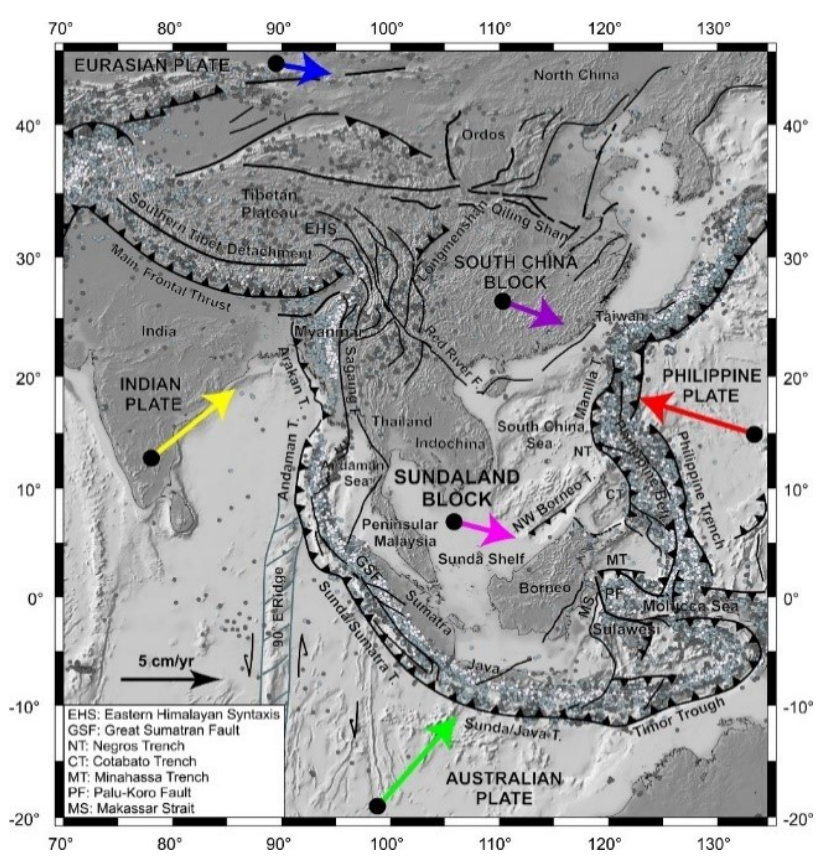

Fig. 1. Absolute/ITRF2000 motions of the Eurasian, Indian, Australian, Philippine plates and the South China and Sundaland blocks (Simons et al, 2007)

Malaysia is considered to be located on the stable part of the Sunda platelet, also known as the Sundaland block (Simons et al., 2007). The Sundaland block (Fig. 1) is mainly surrounded by tectonically active convergent boundaries, at which the Philippine Sea, Australian and Indian Plates are subducting below Sundaland at respectively its eastern, southern and western boundaries. The Eurasian plate and South China block are attached to the north of the Sundaland block. This particular region of South-East Asia is considered to be one of the most seismically active and tectonically complex regions on Earth. The rotation axis of the Sunda Plate, according to (19992004) inter-seismic GPS velocity estimates in ITRF2008, is positioned at $48.05^{\circ} \pm 1.1^{\circ} \mathrm{N},-88.51^{\circ} \pm 0.4^{\circ}$ Eand exhibits a clockwise rotation of $0.341 \pm 0.015$ degrees per Myr (Mustafar et al., 2017). This indicates that the absolute motion of Malaysia as part of Sundaland is $29-32 \mathrm{~mm} / \mathrm{yr}$ in ESE direction. This motion only varies $\pm 1.5 \mathrm{~mm} / \mathrm{yr}$ due to the geographical location of the rotation pole w.r.t. to Peninsular and East Malaysia. In addition, also slightly higher (1-2 $\mathrm{mm} / \mathrm{yr}$ ) and lower (2-5 mm/yr) velocity estimates were observed (Simons et al., 2007; Mustafar et al., 2017) for respectively Peninsular and East Malaysia as a result of their vicinity to the plate boundary deformation zones with the Indian and Australian plates (for Peninsular Malaysia) and the Philippine Sea plate (for East Malaysia). Therefore, it made sense to select a static reference frame (MGRF2000) since the internal network deformation until then on the Peninsular and most of East Malaysia was small.

The demand from diverse applications for high availability, reliability and flexible Global Navigation Satellite System (GNSS) positioning techniques has led DSMM to gradually expand the MASS Network to the Malaysia RealTime Kinematic GNSS Network or MyRTKnet (Jamil et al., 2010). Currently there are 118 CORS incorporated into the MyRTKnet, with spacing of between 30 to $120 \mathrm{~km}$, providing real-time corrections with a latency of under one second using the Virtual Reference Station (VRS) technique. MyRTKnet serves as the backbone for GDM2000 coordinates referencing and dissemination to a variety of users in Malaysia.

While the vast majority of seismicity in South East Asia occurs in the surrounding plate subduction and collision zones (Fig. 1), the Sundaland block interior is only affected by a very low rate of shallow seismicity (Simons et al., 2007). Hence the impact of earthquakes along the Sundaland plate boundaries on the Malaysian reference frame (as co- and post-seismic deformation) was believed to be small, although the small deviations from its absolute motion along the western part of Peninsular Malaysia were associated with elastic loading of the upper Sundaland plate during the inter-seismic phase as a result of strain build-up that reached far inside the Sundaland plate (Simons et al., 2007). This was confirmed when the Mw 9.2 Sumatra-Andaman megathrust earthquake occurred along the Sumatra and Andaman trenches on 26 December 2004. On that Boxing day, instantly vast areas in SE Asia experienced non-uniform co-seismic displacements that reached between $17 \mathrm{~cm}$ at the western edge of the Peninsula to still almost $1 \mathrm{~cm}$ at the eastern edge of Sabah in East Malaysia (Vigny et al., 2005). Subsequent earthquakes along these trenches (2005 Mw 8.6 Nias-Simeulue, 2007 Mw 7.9 Bengkulu and 2010 Mw 7.8 Mentawai (Qiu et al., 2018), as well as the 2012 Mw 8.6 Indian Ocean earth- 
quake (Yadav et al., 2013) also generated additional instant co-seismic deformations in the MyRTKnet network. Additionally the entire network has been undergoing postseismic deformations from these seismic events, in which the contribution of the $2004 \mathrm{Mw} 9.2$ event was most noticable (Gill et al., 2015 and Wan Aris, 2018). Consequently, the GDM2000 coordinates were revised to include deformation corrections for the 2004-2007 period which resulted in the GDM2000(REV 2006). However, continued usage of GDM2000(REV 2006) as a static datum has caused MyRTKnet reference frame coordinates to degrade over time (Rasidi, 2016):

- The entire network generally moves about $3 \mathrm{~cm}$ per year from its original position towards the EastSoutheast;

- Without taking into account the effects of earthquakes, GDM2000 coordinates would already have changed by about $60 \mathrm{~cm}$ in the last 20 years, between 2000 and 2020.

- Post-seismic motions were not accounted for, which in the case of Malaysia approximately have a westward orientation towards the earthquake epicentres along the Sumatra and Andaman trenches, with a magnitude that varies with distance to the origin of each of the seismic events. It effectively means the network is stretched in E-W direction.

- The co- and post-seismic deformation of the $2012 \mathrm{Mw}$ 8.6 and 8.2 Indian Ocean earthquakes were not accounted for, which due to the different nature (strikeslip as opposed to subduction type) resulted in different co- and post-seismic deformation patterns across Malaysia (Wan Aris, 2018 and Yadav et al., 2013).

In order to start address the above issues, a second shortterm solution was implemented by DSMM in 2016 (Rasidi, 2016). A study on the stability of observations at MyRTKnet stations using existing GNSS observation data for the period from March 2016 to July 2016 was carried out. There were two problematic MyRTKnet stations, namely, 1) AMAN in Sarawak indicating the occurrence of tilting and deposition, and 2) KRAI in Peninsular Malaysia that exhibited changes in position due to reconstruction after flood damage in 2014. New MyRTKnet coordinates were computed, based on thirty-day solutions data filter, and linked to fourteen ITRF2014 core stations. Similarity transformation parameters were developed to transform the 2016 reference frame solution to GDM2000(REV 2006) in order to resolve MyRTKnet consumer problems temporarily (Rasidi, 2016).

To prevent further degradation of CORS coordinates, a new time-dependent geodetic reference frame had to be developed for Malaysia based on kinematic and semikinematic conceptual models:

- A kinematic reference frame is where the timedependent elements are modelled as an implicit component of the CORS coordinates. For example, ITRF2014 is a kinematic global reference frame, consisting of coordinates, velocities and post-seismic deformation models defined in a stable terrestrial reference frame (Altamimi et al., 2016). By applying the ITRF2014 kinematic reference frame concept at the national level, a kinematic datum may include a deformation model consisting of a velocity field that allows the estimation of the plate motion at any point in the country and patches of modelled displacements to account for substantial (post-seismic) ground movements (Ronen et al., 2017).

- Continuously changing coordinates in a kinematic datum poses significant challenges for the majority of users of spatial data, particularly in the cadastral database acquired at different epochs that need to be integrated harmoniously to meet the legal requirements. On the other hand, a semi-kinematic reference frame enables the time-dependent coordinates to be transformed consistently and accurately to a fixed reference epoch over time; thus, providing a more practical approach in handling spatial databases coordinate systems (Stanaway et al., 2014 and FIG, 2014).

The term "kinematic" instead of "dynamic" is used in this paper since in the case of geodetic reference frames, station trajectory models are mostly treated as geometrical, i.e. kinematic descriptions of station displacement. The physical processes driving the motion and dynamical behaviour of the solid Earth is of secondary interest (Bevis et al., 2020 and Poutanen et al., 2018).

Many countries have adopted the concept of timedependent coordinates in their geodetic datums in order to prevent degradation of the datum as a function of time, e.g. New Zealand (Blick et al., 2006), Japan (Tanaka et al., 2007), Taiwan (Ching, et al., 2015), Egypt (Rabah, et al., 2016), Israel (Ronen et al., 2017) and Australia (GDA2020, 2018). This study presents the concept of a time-dependent geodetic datum for Malaysia to clearly address the following issues: i) enhancing GDM2000 as a time-dependent geodetic datum; ii) time-dependent reference frame transformation from ITRF2000 to ITRF2014; iii) modelling the MyRTKnet station velocities and post-seismic deformation; iv) realization of new time-dependent geodetic reference frame based on ITRF2014; and v) implications on cadastral, mapping and GIS databases. 


\section{Time dependent coordinates and transformation to ITRF2014}

\subsection{Station trajectory model}

MGRF2000 was implemented through a GNSS network anchored to the Earth's crust and therefore can be called crust or plate-based frame. Tectonic plates are in continuous steady motion; however, when an earthquake occurs, this steady motion is interrupted due to the seismicity of the earthquake. Earthquakes induce crustal deformations are defined in three successive sequences (inter-, co- and post-seismic) and together make up a seismic cycle with a total duration of up to several hundreds of years. Coseismic displacement refers to the displacement that occurs at the instant of the earthquake while the delayed transient deformation of the Earth's crust caused by stress relaxation in the mantle or in the low viscosity layers of the crust is called post-seismic deformation (Sabadini et al., 2004 and Freymueller, 2017). Inter-seismic deformation occurs in the long intervals between earthquakes, once the early transient post-seismic deformation has ceased to be clearly observable, and it is thought to reflect the relatively steady motion at depth (Wright, 2015).

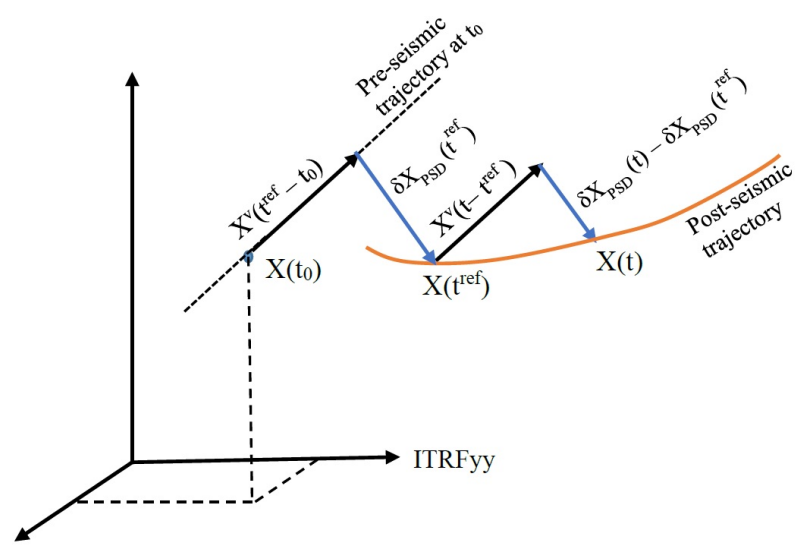

Fig. 2. Time-dependent coordinates: $t_{0}$ and $t^{\text {tref }}$ are the pre-seismic and post-seismic reference epochs, respectively.

After an earthquake, the time-dependent position of a station during the post-seismic trajectory, $\mathrm{X}$ at an epoch $\mathrm{t}$ (Altamimi et al., 2016) can be defined as:

$$
X(t)=X\left(t_{0}\right)+X^{v}\left(t-t_{0}\right)+\delta X_{P S D}(t)
$$

where $t_{0}$ is the pre-seismic reference epoch, $X^{v}$ is the inter-seismic linear velocity due to the plate tectonic motion and, $\delta \mathrm{X}_{P S D}(\mathrm{t})$ is the total sum of the time dependent
Table 2. Types of geodetic reference frames in relation to the timedependent coordinates

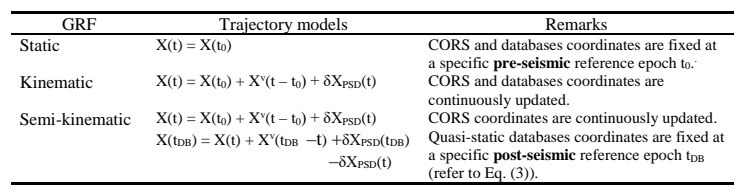

non-linear Post-Seismic Deformation (PSD) deformations at epoch $\mathrm{t}$ (see Fig. 2). The kinematic descriptions of station displacement or trajectory model of a station $\mathrm{X}(\mathrm{t})$, which is given by Eq. (1), can be decomposed in a geocentric cartesian axis system $[\Delta \mathrm{X}, \Delta \mathrm{Y}, \Delta \mathrm{Z}]^{T}$ or in a local or topocentric cartesian axis system $[\mathrm{E}, \mathrm{N}, \mathrm{U}]^{T}$ in which the axes point east, north and up (Jakeli et al., 2017). Analysis of station position time series of the CORS network will provide trajectory model parameters such as seasonal signal, offsets, inter- and post- seismic velocities, instantaneous co-seismic position jumps, and post-seismic (exponential and/or logarithmical decay) displacements (Metivier et al., 2014 and Bos et al., 2020). Section 3.0 describes the details of the geodetic time series analysis of the Malaysian CORS network.

Table 2 provides the description of static, kinematic and semi-kinematic geodetic reference frame (GRF) with respect to the time-dependent coordinates. A semikinematic GRF consists of both kinematic and quasi-static coordinates. The quasi-static coordinates of the spatial databases in a semi-kinematic GRF always refer to a specific epoch and do not vary until they exceed a certain critical level and the GRF is updated, while the CORS kinematic coordinates are updated regularly (Ronen et al., 2017). The coordinates of CORS and spatial databases in a kinematic GRF change regularly with time.

\subsection{Time dependent reference frame transformation}

The transformation from any ITRFyy to ITRF2014 reference frame with data sets at any given epoch $t$ can be given by the time-dependent 14-parameters Helmert transformation (Altamimi et al., 2002):

$$
\begin{aligned}
& X_{\text {ITRF2014 }}(t)=X_{\text {ITRFyy }}(t)+\left(T+T^{v}\left(t-t^{r e f}\right)\right) \\
& +\left(D+D^{v}\left(t-t^{r e f}\right)\right) X_{\text {ITRFyy }}(t)+\left(R+R^{v}\left(t-t^{r e f}\right)\right) X_{\text {ITRFyy }}(t)
\end{aligned}
$$

where $t^{r e f}$ is the reference epoch for ITRF2014, $\mathrm{T}$ is the translation in meter, $\mathrm{D}$ is the unitless scale factor and, $\mathrm{R}$ is the rotation matrix in arc-second. $\mathrm{T}^{v}, \mathrm{D}^{v}$, and $\mathrm{R}^{v}$ are the 
Table 3. Transformation parameters and their rates from ITRF2000 and ITRF2008 to ITRF2014 at epoch 2010.0 (Source: http://itrf.ign.fr/doc_ITRF/Transfo-ITRF2014_ITRFs.txt)

\begin{tabular}{|c|c|c|c|c|c|c|c|c|}
\hline $\begin{array}{r}\text { Parameters } \\
\text { Rate }\end{array}$ & $\begin{array}{c}\mathrm{T}_{\mathrm{X}} \\
\mathrm{mm}^{\mathrm{m}} \\
\mathrm{T}^{\mathrm{v}} \mathrm{x} \\
\mathrm{mm} / \mathrm{y} \\
\end{array}$ & $\begin{array}{c}\mathrm{T}_{\mathrm{Y}} \\
\mathrm{m}_{\mathrm{m}} \\
\mathrm{T}^{\mathrm{v}} \mathrm{Y} \\
\mathrm{mm} / \mathrm{y} \\
\end{array}$ & $\begin{array}{c}\mathrm{T}_{\mathrm{Z}} \\
\mathrm{mm} \\
\mathrm{T}_{\mathrm{z}} \\
\mathrm{mm} / \mathrm{y} \\
\end{array}$ & $\begin{array}{c}\mathrm{D} \\
\mathrm{ppb} \\
\mathrm{D}^{\mathrm{v}} \\
\mathrm{ppb} / \mathrm{y}\end{array}$ & $\begin{array}{c}R_{x} \\
0.001 " \\
R_{x} x_{x} \\
0.001^{\prime \prime} / y \\
\end{array}$ & $\begin{array}{c}\mathrm{R}_{\mathrm{Y}} \\
0.001^{\prime \prime} \\
\mathrm{R}_{\mathrm{Y}} \\
0.001{ }^{\prime \prime} / \mathrm{y}\end{array}$ & $\begin{array}{r}\mathrm{R}_{\mathrm{z}} \\
0.001 " \\
\mathrm{R}^{\mathrm{v}} \mathrm{z} \\
0.001 \% / \mathrm{y}\end{array}$ & Epoch \\
\hline \multicolumn{9}{|l|}{ RF2000 } \\
\hline Parameters & -0. & -1. & +26.1 & -2.12 & 0.00 & 0.00 & 0.00 & 2010.0 \\
\hline Rates & -0 & -0.1 & +1.9 & -0.11 & 0.00 & 0.00 & 0.00 & \\
\hline \multicolumn{9}{|l|}{ ITRF2008 } \\
\hline Parameters & -1.0 & -1.5 & -2.4 & & & & 0.0 & 2010.0 \\
\hline Rates & 0.0 & 0.0 & +0.1 & -0.03 & 0.00 & 0.00 & 0.00 & \\
\hline
\end{tabular}

rates per year of the translation vector, scale factor and rotation matrix, respectively. Table 3 provides the transformation parameters and their rates from ITRF2000 and ITRF2008 to ITRF2014.

The time-dependent position of $\mathrm{X}_{\text {ITRFyy }}(\mathrm{t})$ with respect to a post-seismic reference epoch $\mathrm{t}^{\text {ref }}$ is derived from Eq. (1) as follows (refer to Fig. 2):

$$
\begin{aligned}
& X_{\text {ITRFyy }}(t)=X_{\text {ITRFyy }}\left(t^{r e f}\right)+X_{\text {ITRFyy }}^{v}\left(t-t^{r e f}\right) \\
& +\delta X_{P S D}(t)-\delta X_{P S D}\left(t^{r e f}\right)
\end{aligned}
$$

Substitute $\mathrm{X}_{\text {ITRFyy }}(\mathrm{t})$ in Eq. (2) with the expression given by Eq. (3), and omitting the negligible terms we have:

$$
\begin{aligned}
& X_{\text {ITRF2014 }}(t)=X_{\text {ITRFyy }}\left(t^{r e f}\right)+\left(T+T^{v}\left(t-t^{r e f}\right)\right)+(D \\
& \left.+D^{v}\left(t-t^{r e f}\right)\right) X_{\text {ITRFyy }}\left(t^{r e f}\right)+\left(R+R^{v}\left(t-t^{r e f}\right)\right) X_{\text {ITRFyy }}\left(t^{r e f}\right) \\
& +X_{\text {ITRFyy }}^{v}\left(t-t^{r e f}\right)+\delta X_{P S D}(t)-\delta X_{P S D}\left(t^{r e f}\right)
\end{aligned}
$$

The first parts of Eq. (4) transforms ITRFyy reference frame origin, scale and orientation at epoch $\mathrm{t}^{\text {ref }}=2010.0$ to epoch t; while the last three parts update the ITRFyy coordinates to account for (linear) tectonic plate motion and any (non-linear) post-seismic deformation up to epoch $\mathrm{t}$. If $\mathrm{t}=\mathrm{t}^{\text {ref }}$, then Eq. (4) reduces to a 7-parameter static datum transformation model: $\mathrm{X}_{\text {ITRF2014 }}\left(\mathrm{t}^{\text {ref }}\right)=\mathrm{X}_{\text {ITRFyy }}\left(\mathrm{t}^{r e f}\right)+\mathrm{T}+$ $\mathrm{DX}_{\text {ITRFyy }}\left(\mathrm{t}^{\text {ref }}\right)+\mathrm{RX}_{\text {ITRFyy }}\left(\mathrm{t}^{\text {ref }}\right)$.

By propagating MGRF2000 coordinates from the preseismic reference epoch $\mathrm{t}_{0}=2000.0$ to ITRF2014 reference epoch $\mathrm{t}^{r e f}=2010.0, \mathrm{X}_{\text {ITRF2000 }}\left(\mathrm{t}^{r e f}\right)$ in Eq. (4) is given as follows:

$$
\begin{aligned}
& X_{\text {ITRF2000 }}(2010.0)=X_{\text {ITRF2000 }}(2000.0) \\
& +10 y r . X_{I T R F 2000}^{v}+\delta X_{P S D}(2010.0)
\end{aligned}
$$

The station velocities in ITRF2000 can be derived from the velocity model in ITRF2014 (Altamimi, et al., 2002):

$$
X_{I T R F 2000}^{v}=X_{I T R F 2014}^{v}-T^{v}-D^{v} X_{I T R F 2000}-R^{v} X_{I T R F 2000}
$$

\section{Analysis of station position time series of the Malaysian CORS network}

\subsection{Geodetic reference frame}

The current Malaysian Geodetic Reference Frame called MGRF2000 was previously aligned to ITRF2000 (Altamimi et al., 2002) and consists of 79 points with their static coordinates at epoch 2000.0 that were revised in 2006. Taking advantage of the availability of the GNSS/GPS data of the CORS network in Malaysia, notably the Malaysia Active GPS System (MASS) and Malaysia Real-Time Kinematic GNSS Network (MyRTKnet), a more accurate and robust Malaysian geodetic reference frame can be determined, fully aligned and compatible with the ITRF2014 (Altamimi et al., 2016). For that purpose, DSMM undertook the re-computation of daily position solutions for the entire Malaysian CORS and International GNSS Service (IGS) subset network and generated new position time series for further analysis and realization of a new solution to be considered as the basis of the new Malaysian Geodetic Reference Frame 2020 (MGRF2020).

By August 2019, DSMM made available the daily SINEX file solutions generated with the Bernese GNSS software that covered a time-span from 1999 to 2018. Detailed analysis of the station position time series using CATREF software developed by IGN (France)(Altamimi et al., 2006) was then carried out in order to check the quality of the daily solutions and their appropriateness for the numerical realization of the MGRF2020. The analysis included in particular i) the detection and assignment of station position discontinuities due to earthquakes and equipment changes, ii) the adjustment of parametric models describing the Post-Seismic Deformation (PSD) for sites subject to major earthquakes and, iii) to generate a cumulative long-term solution of station positions and velocities of the Malaysian CORS network to be considered as the basis of the MGRF2020.

\subsection{Input data}

The input data consists of daily station position time series of all Malaysian CORS network provided in the form of Normal Equations (NEQs) generated by DSMM using the Bernese GNSS software version 5.0. In total 7281 daily NEQs were available, covering the time-span 1999.0 2018.96 and comprising 174 sites: 118 Malaysian CORS 


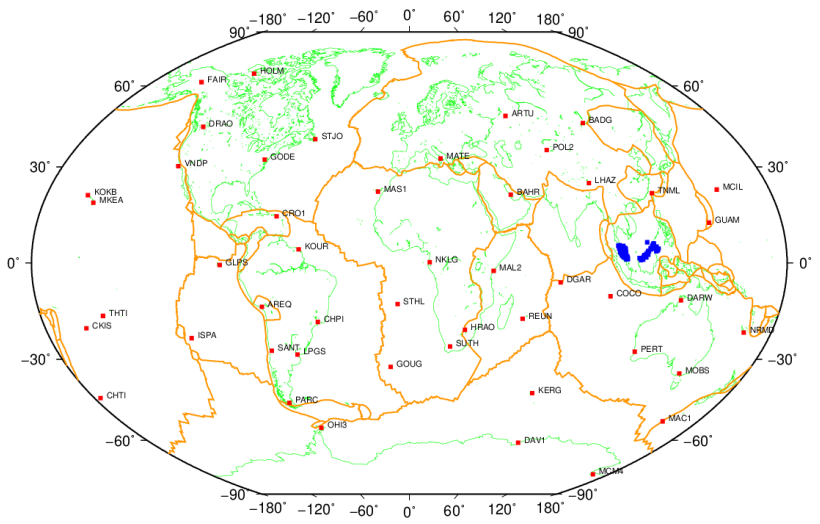

Fig. 3. Distribution of the processed stations where the red dots are the IGS14 Core sites

and 60 IGS stations, as illustrated by Fig. 3 and 4. Figure 4 displays the (magnified) distribution of the Malaysian CORS. The 118 Malaysia sites in MGRF2020 network consists of currently active MyRTKnet stations, decommissioned MyRTKnet stations, and Marine Geodetic Network (MGN) stations. Seventy-nine (79) stations are in Peninsular and remaining thirty-nine (39) stations are in East Malaysia. Therefore, stations with complete data set for the timespan will have 7281 coordinate solutions, which are mainly the MASS stations that remained operational as part of the MyRTKnet. They initial MyRTKnet (27 stations) became fully operational by the end of 2004. There were three (3) sites with coordinate solutions spanning less than one (1) year data; namely, Layang-Layang (LYG2), Kudat (KUDA) and Tawau (TAWA). Station LYG2 consists of 208 coordinates solutions is a remote marine CORS station established in 2014, located in the South China Sea Spratly area.

\subsection{Data analysis}

The data analysis of the station positions time series of the Malaysian CORS network was operated using the CATREF software for the analysis and computation of the ITRF. The CATREF software is well suited and adapted for time series analysis, stacking, combination and velocity estimation. The stacking of the time series generates station positions at a reference epoch, station velocities, station position offsets due to possible discontinuities and time series of station position residuals. The CATREF analysis of the Malaysian daily solutions consists of the following steps:

- Inverting each individual normal equation system using the minimum constraints approach following the procedure that is usually applied in the computation of the ITRF (Altamimi et al., 2002 and Altamimi et al., 2016).

- The daily solutions were analyzed and rigorously stacked to produce mean station positions at a reference epoch, station linear velocities and time series of station position residuals. During this process, discontinuities of the individual station positions time series due to earthquakes and equipment changes were assigned.

- PSD parametric models were determined for stations subject to major earthquakes, following the procedure applied in the generation of ITRF2014 (Altamimi et al., 2016). PSD corrections were then applied to the daily station coordinates prior to the stacking by the main combination software of the CATREF package. Figure 5 illustrates the trajectory of Gua Musang station (GMUS), as an example of a station impacted by the (above mention) major earthquakes in 2005 (Mw 8.6), 2007 (Mw 7.9) and 2012 (Mw 8.6). Both the instant (co-seismic at the (green) earthquake epochs) and non-linear post-seismic displacements can be observed. The station location was also already experiencing post-seismic deformation from the $2004 \mathrm{Mw}$ 9.2 Sumatra-Andaman at the beginning of the position time series in 2005.

- Identify, correct for, reject or down-weight outliers. The rejection of outliers is performed iteratively, starting with the most significant ones, and gradually down to the threshold. The commonly adopted threshold for outlier rejection in ITRF and IGS type analysis is $5 \mathrm{~cm}$ (raw residuals) and $5 \mathrm{~mm}$ (normalized residuals) (see Altamimi et al., 2016). Threshold values could be re-configured as a function of the quality, the timespan and the noise level and characteristic of the daily solutions.

- Discriminate between real outliers and discontinuities due to equipment changes, geophysical phenomena or local dislocation (e.g. ground ruptures due to earthquakes). At this stage, inspection of the time series of the station position residuals is very critical and requires visualization of the residuals, station-bystation.

- Check if the initially introduced discontinuities are statistically significant and justified, discard unnecessary discontinuities, and add other pertinent ones if necessary.

- Iterate the combination as necessary, until no outliers or discontinuities remain.

- Re-run the combination including the estimation of the seasonal signals (annual and semi-annual terms) to account for loading effects due to the atmospheric 


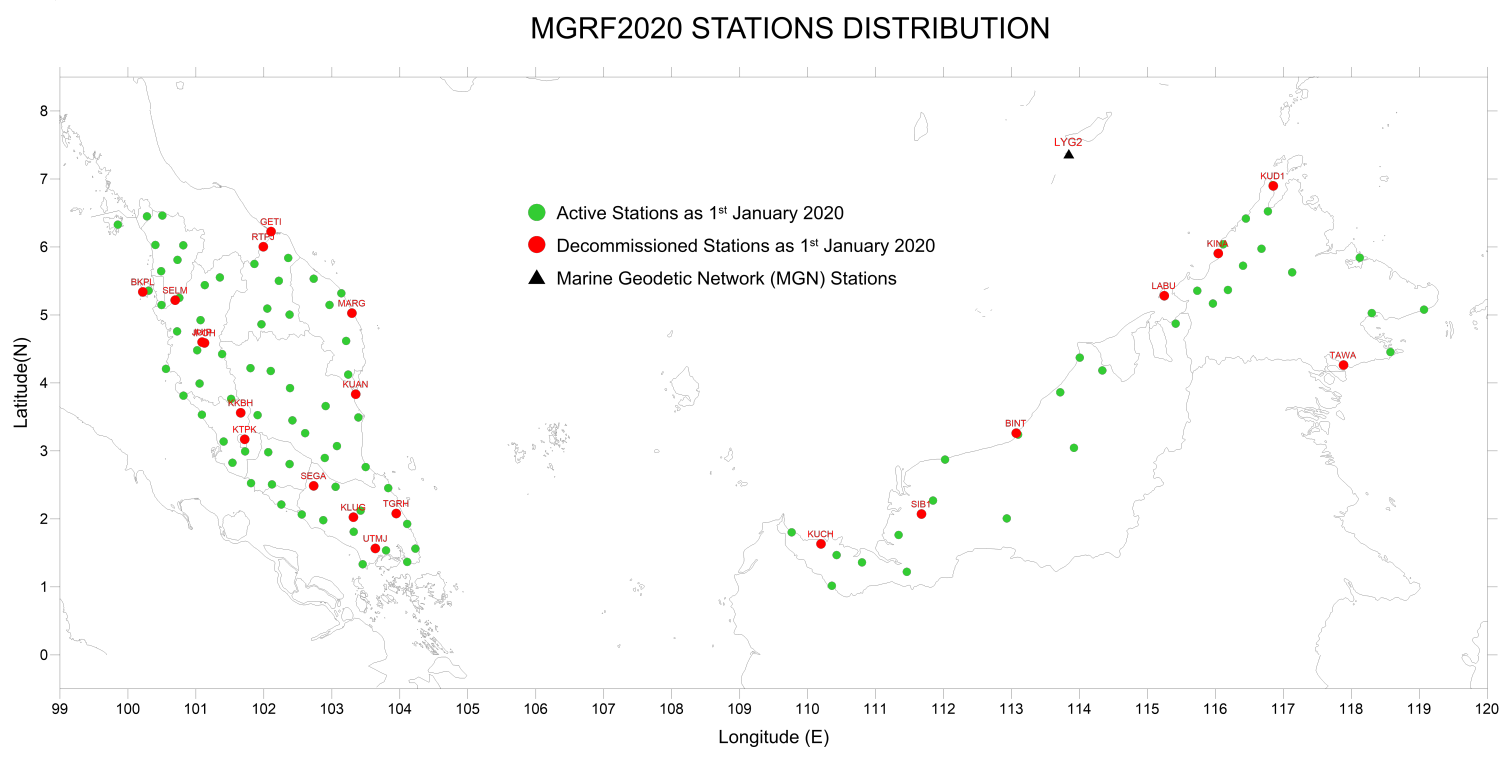

Fig. 4. Distribution of the Malaysian CORS included in the processing (green circle = active station; red circle $=$ decommissioned station as $1^{\text {st }}$ January 2020; blue triangle =marine geodetic network station)

pressure, ocean circulation and terrestrial hydrology. The estimation of seasonal signals has the advantage to improve the linear station velocity determination and facilitate the detection of discontinuities.

- Re-run the combination using the option allowing the proper alignment to IGS14 /ITRF2014, via minimum constraints approach, upon the selected set of highperformance reference stations globally distributed, as depicted in Fig. 3. The IGS14 is the latest global reference frame solution of the IGS (Rebischung and Schmid, 2016) and is based on the ITRF2014.

- Check and validate the alignment of the cumulative solution to IGS14. This step is usually achieved by estimating a 14-parameter transformation (origin, scale, orientation and their time derivatives) between the generated cumulative solution and IGS14, via the selected set of reference frame stations. Not only the 14 parameters should all be zeros (with reasonably small uncertainties at the $1 \mathrm{~mm}$ level), but post-fit residuals of the 14-parameter transformation should all be small, i.e. less than $1 \mathrm{~cm}$ in position and 3 $\mathrm{mm} / \mathrm{yr}$ in velocities. Here too, these threshold values could/should be re-configured as a function of the noise characteristics of the cumulative solution and the time span of the daily solutions. Stations with large position and/or velocity residuals should be rejected from the list of reference frame stations and the combination iterated as necessary.

- The generation of the cumulative solution is a critical and delicate part, because the quality control and the optimal alignment to IGS14 solution should be ensured. Therefore, this process cannot entirely be executed in an automatic way, and manual interventions and inspection of the results, on a site-by-site basis, are usually operated. We apply a rigorous and scientific analysis here, in the same way as we generate an ITRF solution that cannot be fully automated.

\subsection{Realization of the MGRF2020}

The cumulative solution obtained from the stacking of the Malaysian CORS time series of station positions is proposed to be the basis of the MGRF2020 realization. It consists of station position at epoch 2020.0, station velocities and PSD parametric models for stations that were subjected to major earthquakes. The quality of this solution can be judged by the average of the Weighted Mean Root Square (WRMS) values computed the position residuals of each single daily solution for all stations with respect to their computed position using the MGRF2020 reference frame. The time series of the WRMS values of the 7281 daily solutions (ending at 2018.96) is illustrated by Fig. 6. The averages of the WRMS values are 3.0, 3.2 and 7.6 $\mathrm{mm}$ in east, north and vertical components, respectively. The higher WMRS value for the vertical component is related to seasonal variations that affect the vertical positions, like tropospheric water vapor, which has higher variability in tropical regions and hence is more sensitive to mismodelling. Another possible reason is that elevation 


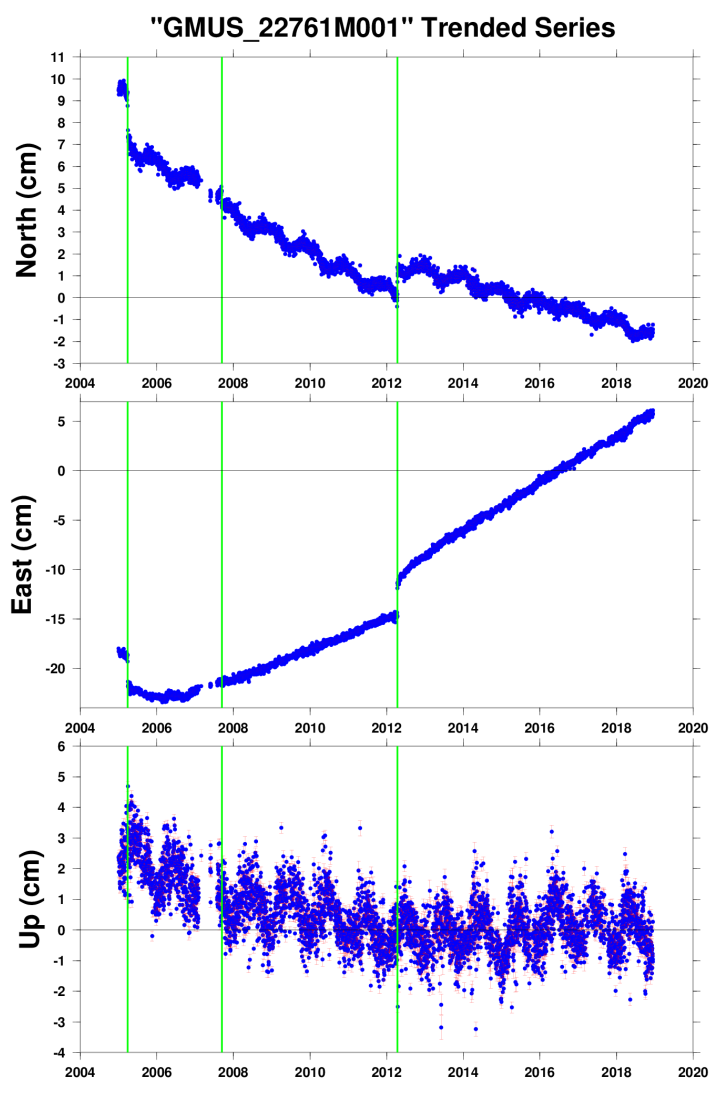

Fig. 5. Trajectory of Gua Musang station (GMUS), as an example of a station impacted by major earthquakes (2004 Mw 9.2 SumatraAndaman, 2007 Mw 7.9 Bengkulu and 2012 Mw 8.6 Indian Ocean earthquakes)

angle-dependent errors tend to affect the vertical component more than the horizontal components (Mao et. al., 1999).

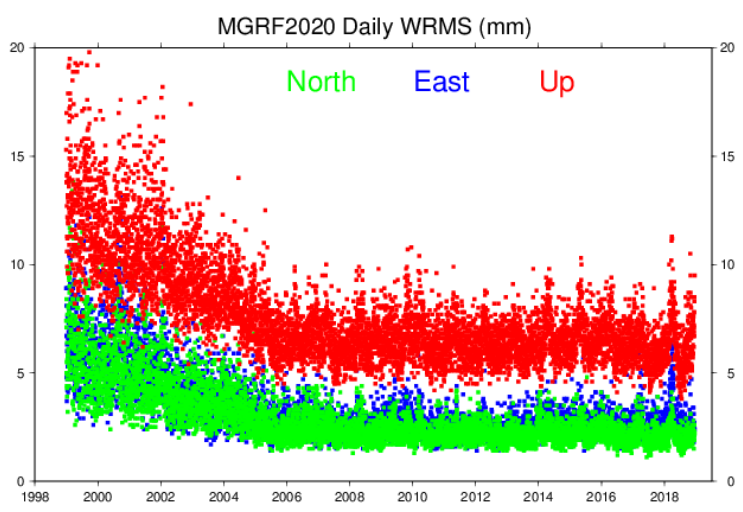

Fig. 6. MGRF2020 Daily WRMS

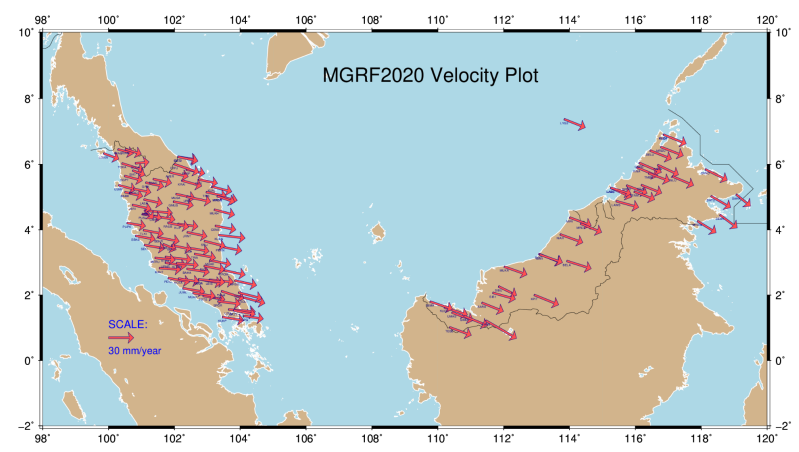

Fig. 7. Horizontal velocities of the Malaysian network

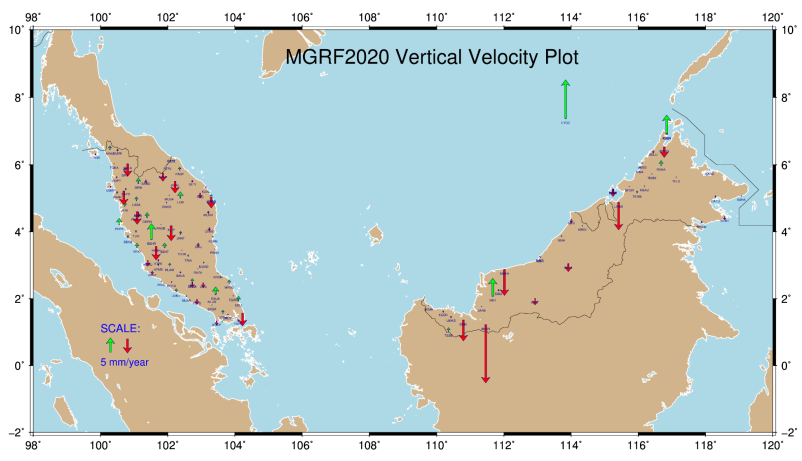

Fig. 8. Vertical velocities of the Malaysian network

Figures 7 and 8 illustrate the horizontal and vertical velocity fields in IGS14 for the Malaysian CORS network at present. These were obtained from stacking all station positions time series to produce the corresponding cumulative solution. The plotted horizontal velocities (Fig. 7) largely resemble the absolute plate motion of the Sundaland block. The vertical velocities (Fig. 8) can only result from either plate deformation or local effects related to either (human) induced subsidence or issues with the CORS station monument stability.

\subsection{CORS station stability analysis}

Analysis of the coordinate time series used to estimate the vertical motions (Fig. 8) shows several stations with suspected vertical stability. Five stations in East Malaysia, namely AMAN, SIMU, MUKA, LAWS and MRDU and another four stations in Peninsular Malaysia, namely as TOKA, KLIP, KRAI and MERU clearly show local subsidence trends that are offset with those of other stations in their region. Figure 9 shows the vertical time-series of 


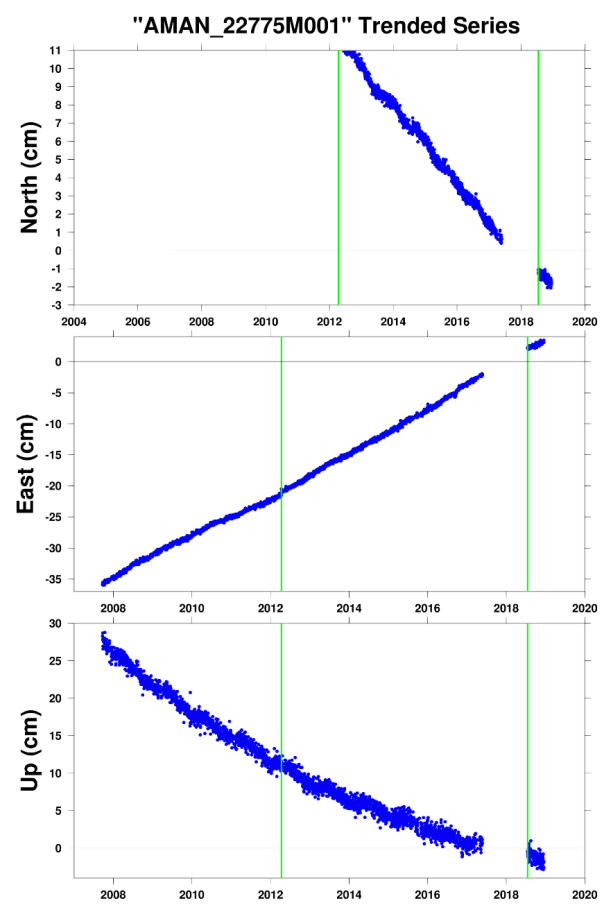

(a) Aman

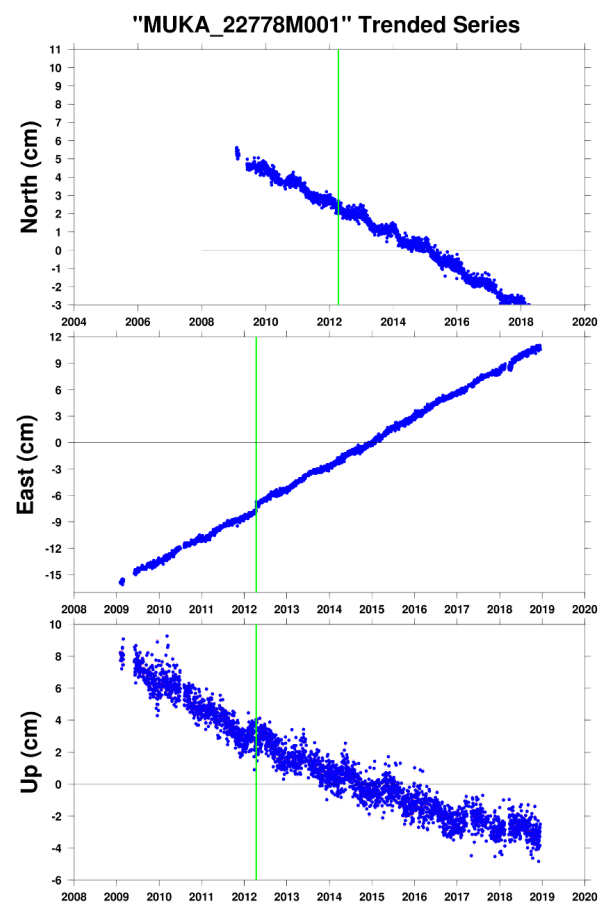

(b) Muka

Fig. 9. Vertical time-series at (a) AMAN and (b) MUKA

AMAN and MUKA stations. Station AMAN exhibits a subsidence rate of up to $20 \mathrm{~mm} /$ year and lesser rates are observed for the other stations mentioned above. These can be attributed to either monument instability and/or local land subsidence due to ground water extraction or (in East Malaysia) local tectonic processes (Mustafar et al, 2017). DSMM will take immediate action to further investigate and if required strengthen the foundation of the affected station pillars from further subsidence to prevent degradation of the coordinate's accuracy over time especially in the vertical component.

\section{Gridded CORS stations kinematic parameters}

\subsection{Gridded velocities}

Raw gridded velocities model for Peninsular Malaysia were generated using 79 CORS stations, while for East Malaysia using 38 CORS stations. Station velocity values were taken from the latest time-series solutions. Data filtering process was done using kriging/collocation technique. Due to the sparse CORS/MyRTKnet stations interval between 30 to $70 \mathrm{~km}$, the grid mesh was set at 5 arc minutes $(\sim 9 \mathrm{~km})$ for Peninsular Malaysia and 10 arc minutes $(\sim 18 \mathrm{~km})$ for East Malaysia. Stations with suspected outliers as shown in the coordinate time-series plots were removed iteratively. The filtered final gridded velocity model for Peninsular Malaysia was obtained after the removal of 15,14 and 16 velocity components in respectively the north, east and vertical direction. Similarly, for East Malaysia, the filtered velocity model was generated after the removal of respectively 3,5 and 11 velocity components in north, east and vertical direction. The final gridded velocity models for each component have been developed based on kriging, inverse distance and polynomial regression interpolation techniques (DSMM, 2020). The horizontal velocities in Peninsular Malaysia (Fig. 10) vary between $-5 \pm 1 \mathrm{~mm} / \mathrm{yr}$. (Fig 10a) and $24 \pm 4 \mathrm{~mm} / \mathrm{yr}$. (Fig 10b) in respectively the latitudinal and longitudinal direction; the vertical velocity is much less significant at $0.2 \pm 0.3 \mathrm{~mm}$ yr. across the Peninsula (Fig. 10c).

The total magnitude of the horizontal velocity increases from $21 \mathrm{~mm} / \mathrm{yr}$. in the northwest to $28 \mathrm{~mm} / \mathrm{yr}$. in the southeast of the Peninsula, in ESE direction. While the latter value matches the absolute plate motion of the Sundaland plate here (based on 1994-2004 inter-seismic position time series by Mustafar et al. (2017)) the current velocities in the northwest of the Peninsula are still $\sim 10 \mathrm{~mm} / \mathrm{yr}$ slower than they were prior to the $2004 \mathrm{Mw} 9.2$ earthquake. The pattern of the horizontal velocity estimate resembles (a scaled version) of the co-seismic estimates shown in Fig. 


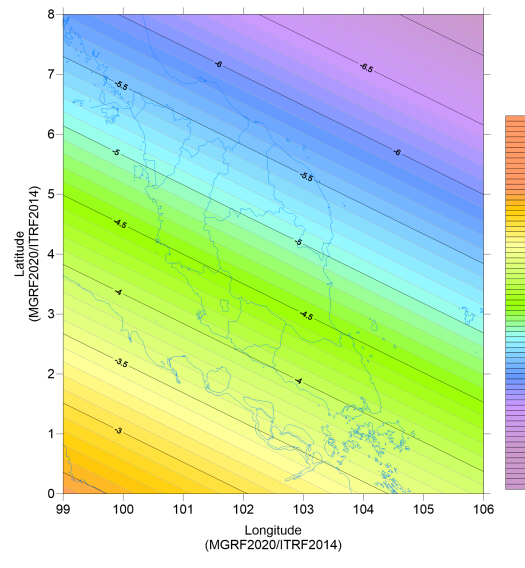

(a)

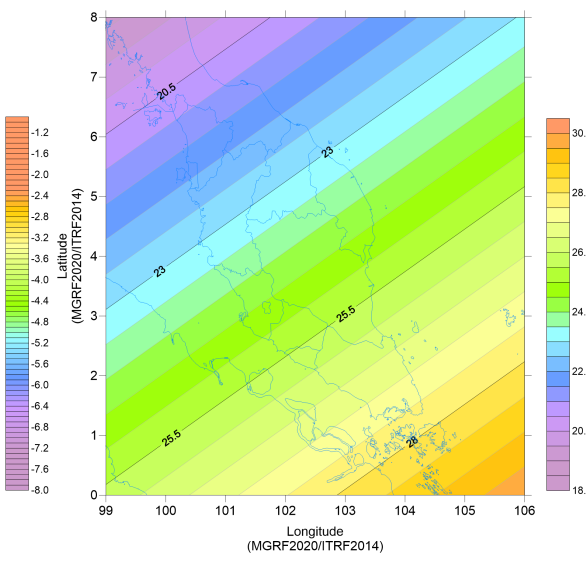

(b)

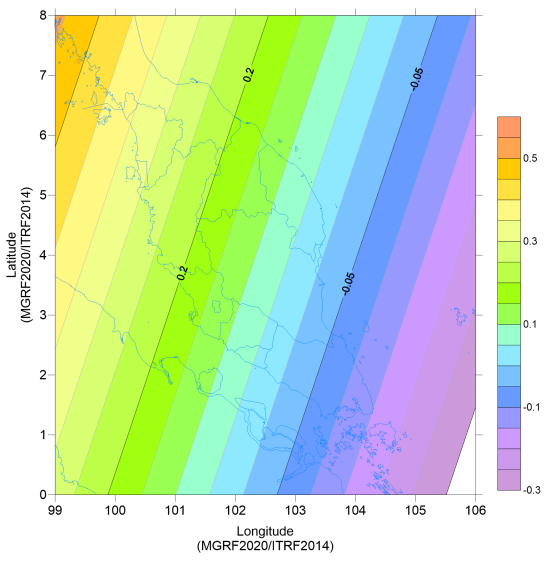

(c)

Fig. 10. (a) North, (b) East and (c) Vertical components of the MGRF2020 (ITRF2014) gridded velocity models in mm/year for Peninsular Malaysia using polynomial regression.

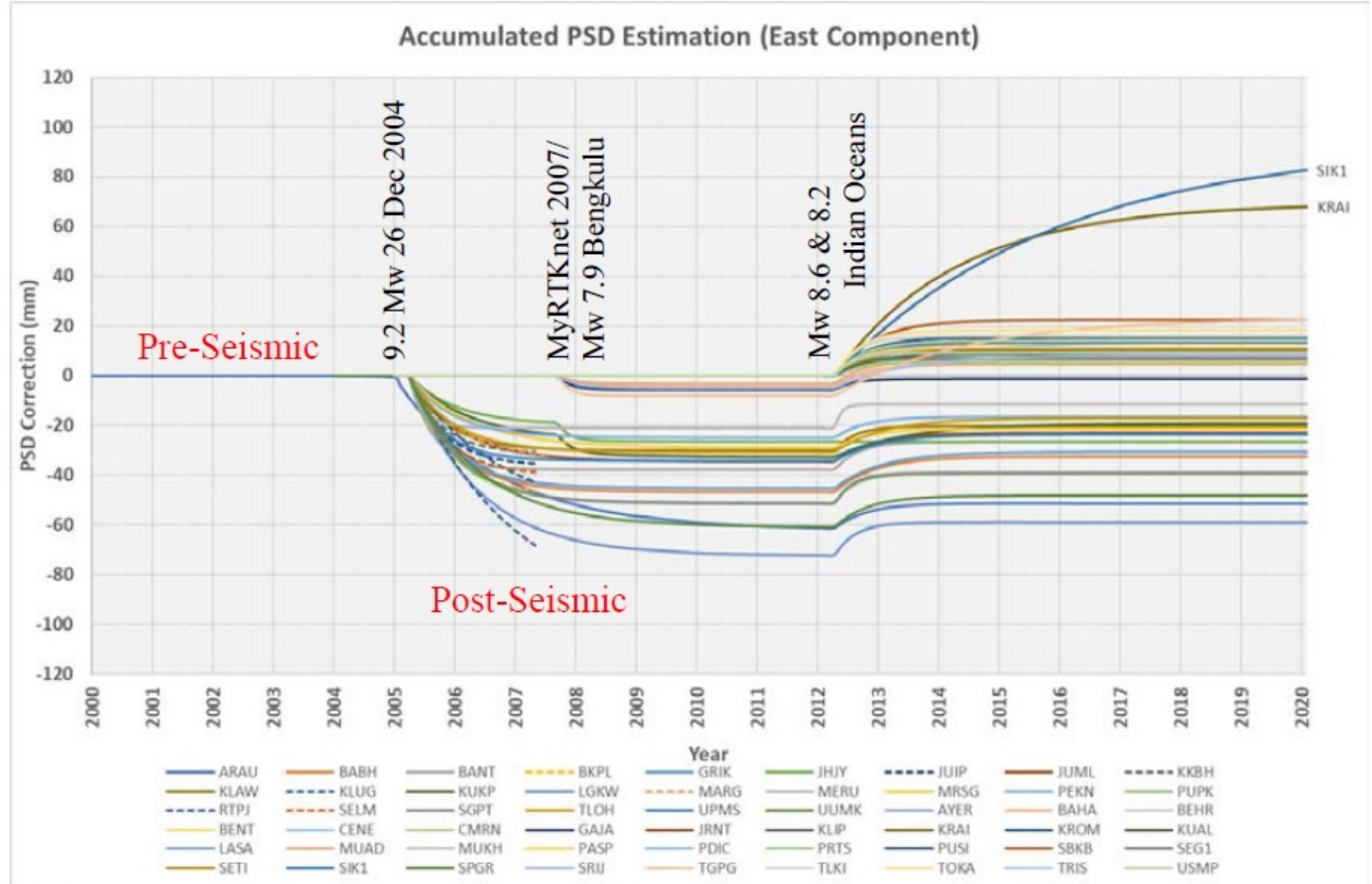

Fig. 11. The nonlinear PSD parametric model trajectories (computed at 30-day intervals) of the Malaysian CORS stations in the E-W direction from epoch 2000.0 (with a big impact from the Mw 9.2 Sumatra-Andaman megathrust earthquake since the end of 2004) to 2020.0. Dashed lines indicate decommissioned CORS stations.

12. Hence the current lower velocity estimates may actually be still quasi-linear and slowly returning back to their inter-seismic values. This is also not unexpected as the post-seismic deformations here might still be detectable in position time series for the coming decades due to the large magnitude of the 2004 event. A similar observation (based on a longer (1994-2018) GPS position time series) was also made at the nearby Phuket Island, Thailand by Simons et al. (2019). 


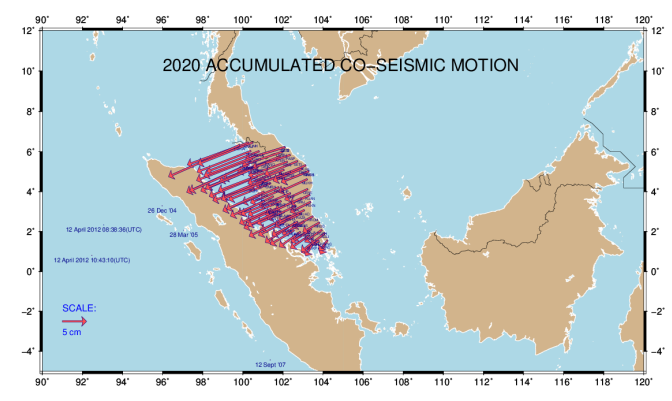

Fig. 12. Accumulated horizontal co-seismic motions of the Peninsular Malaysia CORS stations at epoch 2020.0 due to the $2004 \mathrm{Mw}$ 9.2 Sumatra-Andaman, 2005 Mw 8.6 Nias-Simeulue, 2007 Mw 7.9 Bengkulu, $2010 \mathrm{Mw} 7.8$ Mentawai and $2012 \mathrm{Mw} 8.6$ \& 8.2 Indian Ocean earthquakes.

\subsection{Gridded co-seismic+PSD corrections $\left(\delta \mathrm{X}_{P S D}(\mathrm{t})\right)$}

There were thirty-nine earthquakes with magnitude bigger than 7.0 occurred in Indonesia (Sumatra) and the Philippines (Mindanao region) between 1st January 1999 and 1st January 2019 (U.S. Geological Survey, 2019). However, five major earthquakes in the Sumatra-Andaman area (2004 Mw 9.2 Sumatra-Andaman, 2005 Mw 8.6 Nias-Simeulue, 2007 Mw 7.9 Bengkulu, 2010 Mw 7.8 Mentawai and 2012 Mw $8.6 \& 8.2$ Indian Ocean earthquakes) and one in Mindanao (2013 Mw 7.2Bohol earthquake) have significantly affected the position and velocity of MyRTKnet stations in Peninsular and the North Borneo state of Sabah.

The nonlinear station motions in MGRF2020 were modelled similarly as in ITRF2014 with an enhanced combination strategy, including seasonal (annual and semiannual) signals of station positions, co-seismic jump detections and PSD for sites that were subject to major earthquakes. As such the station position time series are approximated by piecewise linear trends (i.e. an initial position and velocity estimate that are updated whenever (coseismic) position jumps occur), and superimposed with non-linear position corrections (defined after each seismic event) that account for the total accumulated post-seismic deformation (PSD). The PSDs can be described using four parametric models: (1) (Log)arithmic, (2) (Exp)onential, (3) Log + Exp, and (4) Exp + Exp (Altamimi et al., 2016). The PSD parametric models were determined from the MyRTKnet GNSS contributed daily position time series at sites where the PSD was judged to be significant. The adjustment of the PSD parametric models was operated separately for the east, north and up components, taking into account a piecewise linear function, annual and semiannual signals (Altamimi et al., 2016 and Metivier et al.,
2020). The PSD correction for specific epochs was calculated based on the information stored in the PSD's SINEX file. CORS stations affected by the earthquakes in Sumatra and Mindanao have been listed in the SINEX file as one of the data inputs. A total of 55 CORS stations (active and decommissioned) in Peninsular Malaysia are listed in the "psdmodel.snx" file to be used with MGRF2020 coordinates and velocities. Furthermore, for stations affected by multiple earthquakes, the PSD corrections computation will iteratively loop through all earthquake events prior to the epoch date. The total cumulative PSD correction is then applied at the observation epoch.

Figure 11 shows the East component of the PSD parametric model trajectories for 55 CORS stations in Peninsula Malaysia and 2 CORS stations (UMAS and SARA) in East Malaysia. The PSD corrections start in 2005 and were continuously plotted until 2020 at 30-day intervals. However, two stations in Fig. 11, i.e., KRAI, SIK1 clearly show an abnormal trend in the accumulated east component of their PSD corrections. KRAI station was badly damaged during a 2014 flood and was later repaired. For the height component, only BABH station has a significant PSD correction. Therefore, CORS stations with abnormally large PSD corrections (due to local deformation effects) were first eliminated before the final gridding process was undertaken. Further investigation is needed to identify the causes of the abnormally large PSD values at CORS KRAI, SIK1 and BABH.

The total accumulated PSD corrections in Fig. 11 appear inconsistent at some stations in the same region, but this is due to the fact that the available position time series for the MyRTKNet network vary in length. The MyRTKNet was densified twice (in 2007- and 2012-) and hence newer stations (e.g. GAJA (2007-) versus LGKW, ARAU, UUMK and SGPT in the northwest the Peninsula (2004-)) exhibit smaller total accumulated PSD corrections as a result of the $2004 \mathrm{Mw} 9.2$ Sumatra-Andaman megathrust earthquake. This also implies that the linear velocity estimates of these stations differ (e.g. the GAJA linear velocity estimate is $5-8 \mathrm{~mm} / \mathrm{yr}$ larger in ESE direction) as they are based on position time series that are shorter and originate at a later time in the post-seismic deformation phase. The coand post-seismic deformation of the $2012 \mathrm{Mw} 8.6$ and 8.2 Indian Ocean earthquakes, which due to the different nature (strike-slip as opposed to subduction type) resulted in different co- and post-seismic deformation patterns across Malaysia (see Fig. 11 and Yadav et al., 2013). Since postseismic deformation has a logarithmic/exponential decay rate it becomes harder to detect for these newer stations (especially in the absence on inter-seismic velocities at these locations) and hence part of the PSD correction is ab- 
sorbed into quasi-linear velocity estimates. The 1994-2018 horizontal position time series for Phuket Island (Fig. 5 in Simons et al., 2019) confirm this as although the last years of the position time series appears linear, linear velocity estimates based on this more recent period still differ significantly different from their inter-seismic values (19942004).

Therefore, initial offset values were added to the PSD CORS trajectories of these 2007- ( 5 stations) and 2012- (25 stations) at epochs 2007:270 and 2012:120, respectively. These offset values result from interpolation using surrounding original MyRTKnet stations (2004-) so that the total accumulated PSD corrections for all MyRTKnet stations appear consistent. Furthermore, the PSD trajectories shown in Fig. 11 do not include the co-seismic displacements accumulated since the $2004 \mathrm{Mw} 9.2$ SumatraAndaman megathrust event. Therefore, the accumulated co-seismic deformations of CORS stations due to the major earthquakes above were computed at the required epochs (see Fig. 12 for epoch 2020.0). The accumulated co-seismic displacements at a given epoch were then added to the "adjusted" PSD (Fig. $11+$ offset for newer CORS) at the same epoch to generate the cumulative co-seismic+PSD corrections as shown in Fig. 13. The accumulated coseismic+PSD motions have a WSW orientation towards the earthquake epicentres along the Sumatra and Andaman trenches, with a magnitude that varies with distance to the origin of each of the seismic events. Figure 14 shows the distribution of East component of the cumulative co-seismic+PSD corrections for all MyRTKnet stations in Peninsular Malaysia at epochs 2010.0 and 2020.0. The CORS stations located at the NW of Peninsular Malaysia have the largest cumulative co-seismic+PSD displacements of about $20 \mathrm{~cm}$ in the East-component which is mainly associated with the co-seismic deformation following the $2004 \mathrm{Mw} 9.2$ Sumatra-Andaman earthquake (see Fig. 12). Subsequently, we use a grid model to regionally estimate the amount of cumulative co-seismic+PSD correction for the semi-kinematic reference frame.

\section{Coordinates transformation to MGRF2020}

\subsection{Existing geodetic coordinates}

GDM2000@2000.0 coordinates have been affected by several large earthquakes occurring in the neighboring region since the end of 2004. To date, two major revisions of the MyRTKnet station coordinates has been imple-
Table 4. Velocity comparison between derived and published values for Peninsular

\begin{tabular}{lccc}
\hline Method & RMS $_{\text {north }}$ & RMS $_{\text {east }}$ & RMS $_{\text {up }}$ \\
\hline Kriging & $0.32 \mathrm{~mm} / \mathrm{yr}$ & $0.33 \mathrm{~mm} / \mathrm{yr}$ & $0.83 \mathrm{~mm} / \mathrm{yr}$ \\
Inverse Distance & $0.95 \mathrm{~mm} / \mathrm{yr}$ & $1.48 \mathrm{~mm} / \mathrm{yr}$ & $1.22 \mathrm{~mm} / \mathrm{yr}$ \\
Polynomial Regression & $0.96 \mathrm{~mm} / \mathrm{yr}$ & $1.26 \mathrm{~mm} / \mathrm{yr}$ & $1.05 \mathrm{~mm} / \mathrm{yr}$ \\
\hline
\end{tabular}

Table 5. Velocity comparison between derived and published values for East Malaysia

\begin{tabular}{lccc}
\hline Method & RMS $_{\text {north }}$ & RMS $_{\text {east }}$ & RMS $_{\text {up }}$ \\
\hline Kriging & $0.32 \mathrm{~mm} / \mathrm{yr}$ & $0.49 \mathrm{~mm} / \mathrm{yr}$ & $0.54 \mathrm{~mm} / \mathrm{yr}$ \\
Inverse Distance & $0.32 \mathrm{~mm} / \mathrm{yr}$ & $1.25 \mathrm{~mm} / \mathrm{yr}$ & $0.95 \mathrm{~mm} / \mathrm{yr}$ \\
Polynomial Regression & $1.24 \mathrm{~mm} / \mathrm{yr}$ & $1.45 \mathrm{~mm} / \mathrm{yr}$ & $1.00 \mathrm{~mm} / \mathrm{yr}$ \\
\hline
\end{tabular}

mented, namely, in 2006 (GDM2000 REV 2006) and 2016 (GDM2000 REV 2016) to correct for the co-seismic and accumulated post-seismic deformations. Since 2013, DSMM also has been actively involved in the establishment of Marine Geodetic Network (MGN) in the Malaysian Continental Shelf areas. MGN coordinates has been referenced to the IGb08, an updated IGS version of ITRF2008 (Altamimi et al., 2011) and their transformation is discussed in section 5.2.2. The basic formulas to propagate and to transform the existing geodetic coordinates to ITRF2014@2020.0 (or MGRF2020) are given by Eq. (3) and Eq. (4). The prerequisite information for the implementation of these equations are the gridded velocity field and the cumulative coseismic+PSD corrections.

\subsection{Transformation process validation}

\subsubsection{Gridded velocities}

Three interpolation methods were used to generate the gridded velocity models for Peninsular and East Malaysia. To assess the quality of the gridded velocity model, comparison between the published and derived velocity values was carried out. Tables 4 and 5 provide the velocity differences between the derived and published values based on three interpolation methods for Peninsular and East Malaysia, respectively. It can be seen from these tables that the kriging interpolation method gives the best result with the horizontal and vertical velocity differences of better than $0.33 \mathrm{~mm} /$ year and $0.83 \mathrm{~mm} /$ year, respectively. 


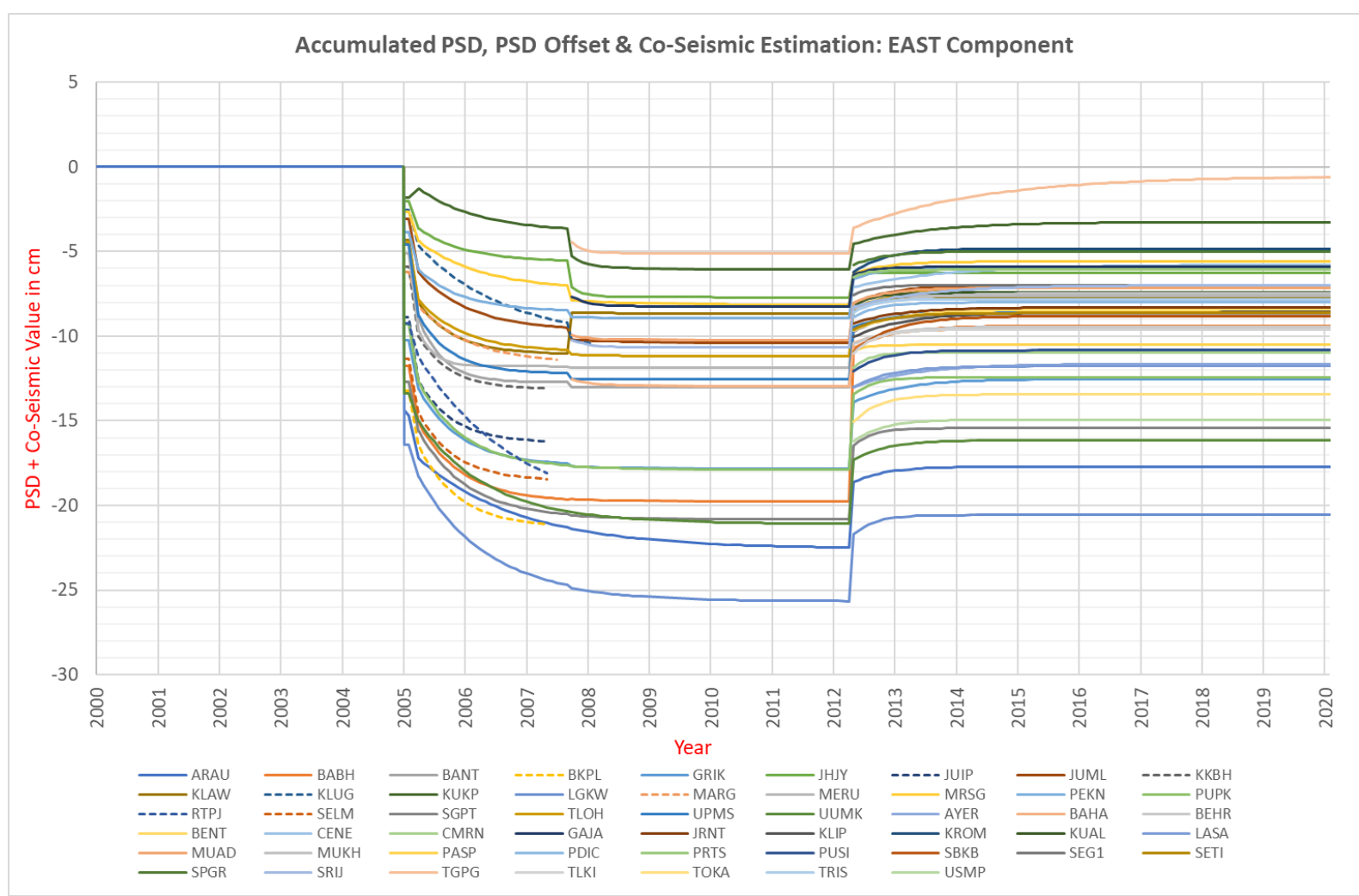

Fig. 13. Filtered co-seismic+ PSD parametric model trajectories (computed at 30-day intervals) of the Malaysian CORS stations in the E-W direction from epoch 2000.0 to 2020. Dashed lines indicate decommissioned CORS stations.

\subsubsection{MGN IGb08 to MGRF2020}

The Marine Geodetic Network (MGN) consisted of 78 MyRTKnet and 50 IGS stations. The MGN network is referenced to IGb08 at epoch 2013.312 (24 April 2013). The following steps have been adopted for the transformation of MGN coordinates to ITRF2014@2020:

i. Apply Eq. (3) for the propagation of MGN coordinates to ITRF2014 reference epoch at $2010.0\left(\mathrm{t}^{\text {ref }}=2013.312\right.$, $t=2010.0)$ :

$\mathrm{X}_{M G N @ 2010.0}=\mathrm{X}_{M G N @ 2013.312}-3.312 \mathrm{yr} . \mathrm{X}^{V}{ }_{I T R F 2008}+$ $\delta \mathrm{X}_{P S D}(2010.0)-\delta \mathrm{X}_{P S D}(2013.312)$

ii. Apply Eq. (4) for the transformation from ITRF2008 to ITRF2014 by setting $\mathrm{R}_{X}=\mathrm{R}_{Y}=\mathrm{R}_{Z}=\mathrm{R}^{v}{ }_{x}=\mathrm{R}_{Y}^{v}=\mathrm{R}_{Z}^{v}=$ $\mathrm{T}^{v}{ }_{x}=\mathrm{T}^{v}{ }_{Y}=0$ (see Table 3):

$$
\begin{aligned}
& X_{M G N / M G R F 2020}=X_{M G N @ 2010.0} \\
& +\left(T+10 y r . T^{v}\right)+\left(D+10 y r . D^{v}\right) X_{M G N @ 2010.0} \\
& +10 y r . X_{I T R F 2014}^{v}+\delta X_{P S D}(2020.0)-\delta X_{P S D}(2010.0)
\end{aligned}
$$

Analysis of the coordinate's differences between the published and derived MGRF2020 indicate that there are several CORS stations with large differences in one or more of the coordinate components. Peninsular Malaysia CORS stations SIK1, TOKA and USMP have large differences in the north component, while stations MERU and UUMK show large differences in the height component. In East Malaysia, station AMAN reveals significance differences in all components, while LAWS, MUKA and NIAH have large differences in the height component. Based upon the coordinates time-series analysis, the problems with these stations originate from either inaccurate antenna heights or concrete pillar subsidence and tilting.

After the removal of the problems relating to these CORS stations, the filtered RMS of MGRF2020 coordinate differences in the north, east and vertical components are respectively 8,13 and $16 \mathrm{~mm}$ for the Peninsular and 8, 9 and $12 \mathrm{~mm}$ for East Malaysia (Table 6). Based on these RMS values, we may conclude that the MGN station coordinates can be transformed to MGRF2020 to within $1 \mathrm{~cm}$ accuracy.

\subsubsection{GDM2000(REV 2016) to MGRF2020}

GDM2000(REV 2016) is the latest revision of GDM2000@2000.0 that has been implemented in 2016. 


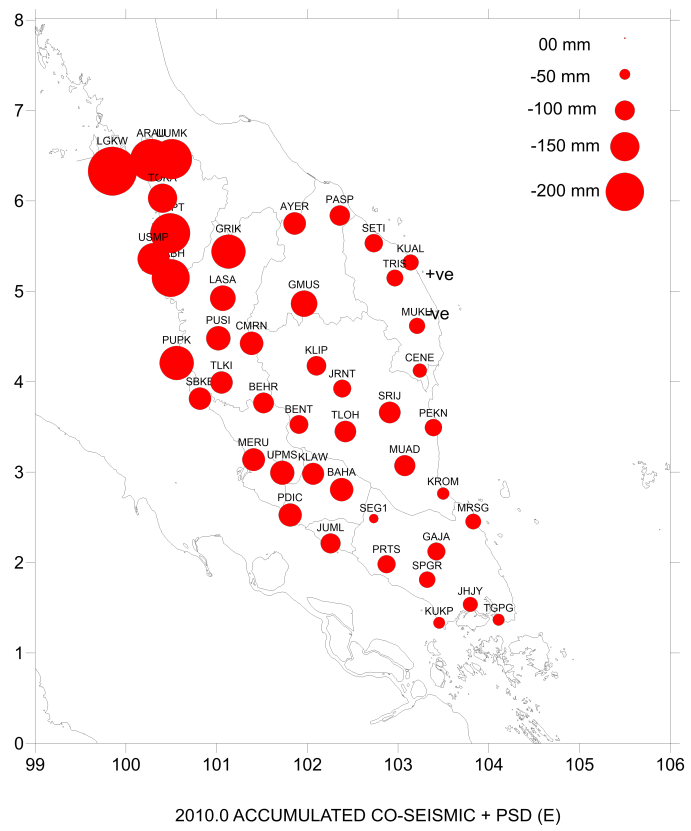

(a)

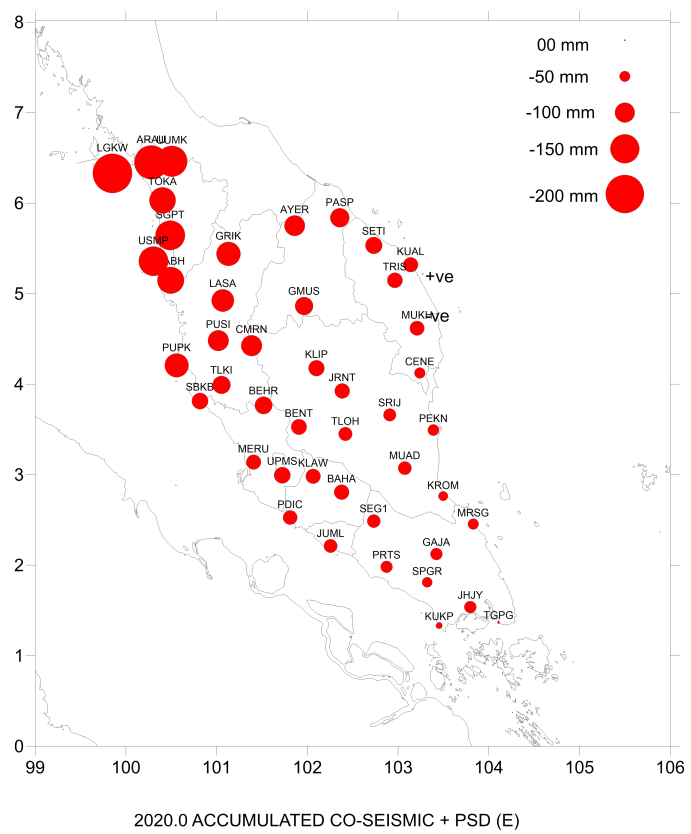

(b)

Fig. 14. East component of the total accumulated co-seismic+ PSD correction at CORS stations in Peninsular Malaysia at epoch (a) 2010.0 and (b) 2020.0. The magnitudes in 2020 have decreased due to the impact of the 2012 Indian-Ocean (strike-slip type) earthquake that resulted in (partially) reversed co- and post-seismic deformation patterns with respect to the previous (subduction type) earthquakes.

The revision was done to minimize the irregularities in GDM2000(REV 2006) coordinates due to the absolute Sundaland plate motion, cumulative post-seismic defor-
Table 6. Unfiltered and filtered RMS of MGRF2020 coordinates differences

\begin{tabular}{lccccccc}
\hline & & \multicolumn{3}{c}{ Unfiltered RMS } & \multicolumn{3}{c}{ Filtered RMS } \\
& & $\mathrm{N}(\mathrm{mm})$ & $\mathrm{E}(\mathrm{mm})$ & $\mathrm{V}(\mathrm{mm})$ & $\mathrm{N}(\mathrm{mm})$ & $\mathrm{E}(\mathrm{mm})$ & $\mathrm{V}(\mathrm{mm})$ \\
\hline \multirow{2}{*}{ MGN(Igb08) } & P. Malaysia & 11 & 25 & 19 & 8 & 13 & 16 \\
GDM2000 & E. Malaysia & 13 & 14 & 34 & 8 & 9 & 12 \\
(REV2016) & . Malaysia & 10 & 20 & 10 & 6 & 9 & 8 \\
GDM2000 & E. Malaysia & 6 & 10 & 24 & 2 & 7 & 14 \\
& P. Malaysia & 15 & 29 & 25 & 15 & 19 & 22 \\
& E. Malaysia & 43 & 30 & 88 & 32 & 25 & 28 \\
\hline
\end{tabular}

mation and other inherited errors that clearly can be seen in the time-series analysis plots. The implementation was carried out using a set of 3-parameter transformation that was derived between MyRTKnet coordinates referred to ITRF2014@2016.3 and GDM2000(REV 2006):

$$
\begin{aligned}
& X_{G D M 2000(R E V 2016)}=X_{G D M 2000(R E V 2006)} \\
& +T_{G D M 2000(R E V 2006) / I T R F 2014 @ 2016.3}
\end{aligned}
$$

where $\mathrm{T}_{\text {GDM2000(REV 2006)/ITRF2014@2016.3 }}$ is the 3parameter translation vector to transform GDM2000(REV 2006) to ITRF2014@2016.3. For the transformation of GDM2000(REV 2016) coordinates to MGRF2020, Eq. (3) is applied $\left(\mathrm{t}^{\text {ref }}=2016.3, \mathrm{t}=2020.0\right)$ :

$$
\begin{aligned}
& X_{G D M 2000(R E V 2016) / M G R F 2020}=X_{G D M 2000(R E V 2016)} \\
& +3.7 y r . X_{I T R F 2014}^{v}+\delta X_{P S D}(2020.0)-\delta X_{P S D}(2016.3)
\end{aligned}
$$

The RMS for misfits in the north, east and vertical components after removing suspected outliers is 6,9 and 8 $\mathrm{mm}$ for Peninsula Malaysia, respectively; while for East Malaysia the values are 2, 7 and $14 \mathrm{~mm}$ (Table 6). Therefore, also all DSMM coordinate products in GDM2000(REV 2016) can be transformed to MGRF2020 within $1 \mathrm{~cm}$ accuracy.

\subsubsection{GDM2000 to MGRF2020}

The most widely used coordinate system in Malaysia is GDM2000(REV 2006) and the positions are referred to ITRF2000@2000.0 with patches applied in 2006. Patches are used to handle unexpected events or jumps in the local or regional crustal motion. The 2006 patches $\left(\Delta \mathrm{X}_{\text {Patch(2006) }}\right)$ basically consisted of the accumulated of co- and post-seismic displacements due to major earthquakes in Sumatra in 2004 and 2005 and/or caused by any local deformations. The 2006 patch is a gridded correction model using polynomial regression applied to GDM2000@2000.0 coordinates. To revert to 
GDM2000@2000.0, the patches need to be removed:

$$
X_{G D M 2000 @ 2000.0}=X_{G D M 2000(R E V 2006)}-\Delta X_{P a t c h(2006)}
$$

The following characteristics need to be considered in the transformation from GDM2000 or GDM2000 (REV 2006) to MGRF2020:

1. The Sundaland plate motion before 25 December 2004 is considered as inter-seismic (linear) motion. Therefore, no PSD corrections for MyRTKnet coordinates were established before 2005 (refer to Fig. 11).

2. Co- and post-seismic displacements for the Mw 9.2 Sumatra-Andaman earthquake on 26 December 2004 and subsequent earthquake events should be applied to GDM2000 and GDM2000 (REV 2006) coordinates before transformation to MGRF2020 (see Fig. 13).

3. The user needs to identify the specific GDM2000 coordinates series that were used. GPS positioning established using the MASS, MyRTKnet or Peninsular Malaysia Primary GPS Network 2000 (PMPGN2000) networks between 2003 and mid-June 2006 was based on GDM2000@2000.0. On the other hand, GDM2000 (REV 2006) was implemented from mid-June 2006 until end of 2015.

Therefore, for the transformation from GDM2000 to GDM2000@2020.0, Eq. (5) and Eq. (4) are modified as follows (taking into account the zero rotation and rotation rates between ITRF2000 and ITRF2014 - see Table 3):

$$
\begin{aligned}
& X_{G D M 2000 @ 2010.0=} X_{G D M 2000 @ 2000.0}+10 y r . X_{I T R F 2000}^{v} \\
& +\delta X_{P S D}(2010.0)
\end{aligned}
$$

$$
\begin{aligned}
& X_{G D M 2000 @ 2020.0}=X_{G D M 2000 @ 2010.0}+\left(T+10 y r . T^{v}\right) \\
& +\left(1+D+10 y r . D^{v}\right) X_{G D M 2000 @ 2010.0}+10 y r . X_{I T R F 2014}^{v} \\
& +\delta X_{P S D}(2020.0)-\delta X_{P S D}(2010.0)
\end{aligned}
$$

PSD corrections were based on the gridded model at epochs 2010.0 and 2020.0. The earlier 2006 patches need to be first removed from GDM2000(REV 2006) coordinates using Eq. (10).

The unfiltered RMS coordinates differences between published and transformed MGRF2020 coordinates for the Peninsula are respectively 15, 29 and $25 \mathrm{~mm}$ in the north, east and vertical components, while for East Malaysia these values are 43, 30 and $88 \mathrm{~mm}$. However, when excluding the large coordinate differences for stations TOKA (all directions) and AYER (in vertical direction) for Peninsular Malaysia, the filtered RMS values are reduced to 15, 19 and $22 \mathrm{~mm}$, and for East Malaysia to 32, 25 and $28 \mathrm{~mm}$ (see Table
6). The estimated transformation accuracy of GDM2000 coordinates propagated over a 20-year time span is considered acceptable for most general surveying, cadastral and mapping applications. GDM2000@2000.0 was processed using only 11 IGS stations surrounding Malaysia and as indicated in Fig.6, the WRMS values of 1999 - 2004 indicate lesser optimum solutions.

\section{Semi-kinematic geodetic datum for Malaysia: GDM2020}

\subsection{GDM2020 defining parameters}

A more accurate and robust Malaysian geodetic reference frame (MGRF2020) has been determined that is fully aligned and compatible with the ITRF2014. MGRF2020 will serve as the foundation for the new geodetic datum GDM2020. GDM2020 datum will further improve the crustal motion model in the Malaysian region and provide users an accurate and seamless access to the national reference frame through the GNSS positioning services. GDM2020 also will be able to provide a seamless national reference frame for land and the marine areas of Malaysia. The defining parameters of GDM2020 are shown in Table 7. The extent of the GDM2020 shall include all the areas contained within Malaysia's marine jurisdiction and its Continental Shelf.

\subsection{Implications on cadastral, mapping and GIS databases}

GDM2000(REV 2006) datum and the associated plane coordinate projection systems have been extensively used by DSMM for referencing of spatial data such as cadastral, mapping and GIS products (DSMM, 2011). Adopting a new time-dependent geodetic datum will have implications on the spatial plane coordinate reference systems. The National Digital Cadastral Database (NDCDB) has more than 40 million boundary marks that refer to the respective

Table 7. GDM2020 defining parameters and extent

\begin{tabular}{ll}
\hline International Terrestrial Reference Frame & ITRF2014 in origin, scale and orientation \\
National CORS & 114 MyRTKnet stations \\
International GNSS Service (IGS) & 60 IGS stations \\
GPS data time-span & $1999.0-2018.96$ \\
National Geodetic Reference Frame & MGRF2020 \\
Reference epoch for quasi-static spatial databases & 2020.0 \\
Site velocity model & Gridded velocity model in ITRF2014 \\
Post Seismic Deformation (PSD) model & Gridded co-seismic+PSD corrections \\
Reference ellipsoid & GRS80 ellipsoid \\
Height system & MyGeoid2022 \\
GDM2020 extent & Land and marine areas of Malaysia \\
\hline
\end{tabular}


State Transverse Mercator (Cassini) origins, while mapping products refer to a single Oblique Mercator (RSO) Projection System (Kadir et al., 2003). The differences on mapping products moving from GDM2000 to GDM2020 will appear as a small change on the map graticules. However, the NDCDB coordinates are survey accurate coordinates with spatial accuracies of $5 \mathrm{~cm}$ to $10 \mathrm{~cm}$, thus requiring accurate transformation from GDM2000 to GDM2020.
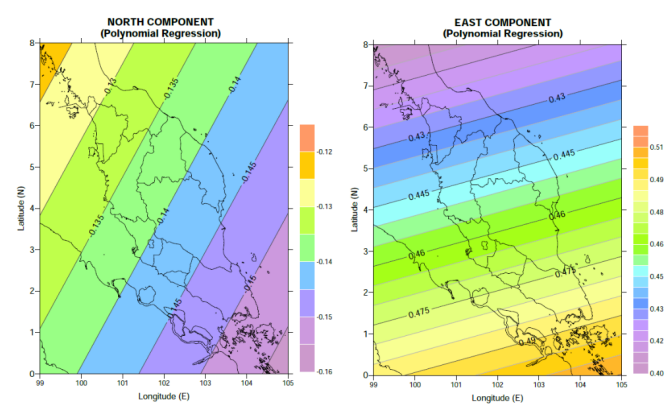

Fig. 15. GDM2000(REV 2006) to GDM2020: Northing and Easting cadastral coordinates shifts for Peninsular Malaysia in meter.

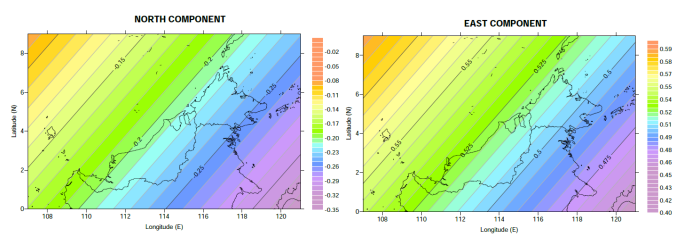

Fig. 16. GDM2000(REV 2006) to GDM2020: Northing and Easting mapping coordinates shifts for East Malaysia in meter.

Datum differences between GDM2000 and GDM2020 may vary as systematic constant corrections from region to region of the Peninsular Malaysia and East Malaysia. These are mainly due to the Sundaland plate motion, different co- and post-seismic deformation patterns within Malaysia and a constant datum shift correction from ITRF2000 to ITRF2014. Therefore, transformation of plane coordinates due to geodetic datum changes may be simplified by gridded Northing and Easting corrections instead of the need for the rigorous transformation. This can be accomplished from the analysis of datum shifts at the MyRTKnet stations (see Fig. 15 and 16).

\subsection{Geoid-based height reference system}

Height reference system modernization envisages a redefinition of the vertical reference system and the realiza- tion of a new vertical reference frame by gravimetric geoid modelling, rather than by geodetic levelling. It enables measurements of elevations with respect to a consistent seamless vertical datum everywhere across the country using GNSS positioning. A precise seamless land-to-sea gravimetric geoid model has been determined for Malaysia primarily from airborne gravity data (Jamil H. et al., 2017 and DSMM, 2020). Airborne gravity data processing was referenced to ITRF2008 and ITRF2014, while the gravimetric geoid was computed on a grid of $1.5 \times 1.5$ arc-minute (corresponding to a roughly $2.7 \mathrm{~km}$ grid) and referenced to GRS80 ellipsoid. The new land-to-sea gravimetric geoid MyGeoid2020 (DSMM, 2020) shall be an integral part of GDM2020.

Within the Malaysia region, the Sundaland tectonic plate motion affects the horizontal position with a velocity of approximately $3 \mathrm{~cm} /$ year but is not significant in the vertical direction (tectonic plates by definition have no vertical motions but can be (vertically) deformed along convergent boundaries with a neighbouring plate) with a velocity of about $0.2 \mathrm{~mm}$ /year (see Fig. 10). Hence, GNSS levelling $(\mathrm{H}=\mathrm{h}-\mathrm{N})$ in Malaysia is least affected by tectonic plate motion; local phenomena such as (human induced) land subsidence and temporal tectonic induced uplift and subsidence as part of a seismic (deformation) cycle has more influence on vertical changes. However, in order to achieve GNSS levelling accuracy of less of than $\pm 2 \mathrm{~cm}$, GNSS data shall be processed rigorously referenced to GDM2020 to produce ellipsoidal height ( $h$ ) accuracies of less than $\pm 1 \mathrm{~cm}$ (Mohamed et al., 2018).

\section{Conclusions and recommendations}

User requests together with increasing accuracy of GNSS positioning will set new demands for national reference frames and their timeliness, for example, the disparity brought about by the increasingly widespread use of Precise Point Positioning (PPP) and the sensitivity of this technique to the reference frame of the orbits and deformation of the Earth due to plate tectonic activity. Furthermore, to prevent the degradation of CORS coordinates over time and disruptions to MyRTKnet services, a new timedependent national geodetic reference frame (MGRF2020) has been developed for Malaysia based on the kinematic and semi-kinematic conceptual models. Taking advantage of the availability of the GNSS data of the CORS network in Malaysia, notably MASS and MyRTKnet, the new MGRF2020 is more accurate and robust than the earlier 
MGRF2000 and has been determined fully aligned and compatible with the ITRF2014.

Given the good quality of the GNSS time series analysis presented in this study, we recommend to DSMM to consider the cumulative solution as the basis for the definition and adoption of MGRF2020, in replacement of the current GDM2000. We further recommend to:

- Provide static coordinates at epoch 2020.0 for operational surveying, mapping and GIS applications;

- Provide the kinematic MGRF2020 solution (station positions, velocities and PSD parametric models) together with the coordinate transformation application software package to users;

- Gradually transform DSMM mapping, cadastral and GIS databases into MGRF2020;

- Consider updating the cumulative solution (MGRF2020) to monitor the still ongoing postseismic deformation in SE Asia and be prepared to include the co- and post-seismic deformation of any future major earthquakes and improve Bernese processing experience by rejecting imprecise data at the observation level. DSMM may hereby also consider an additional (automatized) scientific software package (e.g. zero-difference based) to compare and validate GNSS processing results.

- In order to better use GNSS time-series at the newer CORS (2007- and 2012-) stations with incomplete time series, the inter-seismic velocities can be estimated at these locations by spatial interpolation from surrounding stations with pre-seismic observations. With the constrained inter-seismic velocities, post-seismic movements at the sites without pre-seismic observations can easily be approximated (Chen et al., 2020).

MGRF2020 kinematic coordinates may be updated on a monthly basis from the thirty-day GNSS solutions to provide highest accuracy and efficient MyRTKnet positioning service to the users. The quasi-static spatial databases may be revised every five years (at epoch 2025.0, 2030.0, etc.)or at an earlier date to cater for Sundaland plate motion and deformation. For geospatial data users that maintain their spatial databases at a specific reference epoch, the coordinates at observation epoch (t) from the MyRTKnet positioning service or PPP technique can be updated to the database reference epoch $\left(\mathrm{t}_{D B}\right)$ with the forward updating $\left(\mathrm{t}<\mathrm{t}_{D B}\right)$ or reverse updating ( $\left.\mathrm{t}>\mathrm{t}_{D B}\right)$ using Eq. (3): $\mathrm{X}\left(\mathrm{t}_{D B}\right)$ $=\mathrm{X}(\mathrm{t})+\mathrm{X}^{v}\left(\mathrm{t}_{D B}-\mathrm{t}\right)+\delta \mathrm{X}_{P S D}\left(\mathrm{t}_{D B}\right)-\delta \mathrm{X}_{P S D}(\mathrm{t})$. The updating of observed GNSS coordinates to the database reference epoch will allow for the spatial databases to remain static for a certain period of time. The PSD model and velocity field has to be auto-updated continuously beyond 2020.0 to cater for the updating process of GNSS coordinates.

While the MGRF2020 is a significance advance for more accurate national mapping, cadastral and GIS applications, the first version of the new reference frame may not yet be ideally suited for detailed scientific (geodynamic) investigations. The main reason for this is that the velocity estimates and PSD models were derived from CORS station position time series that have different observation time spans and for the majority originate in the (still ongoing) post-seismic deformation phase following the $2004 \mathrm{Mw} 9.2$ Sumatra-Andaman earthquake. While the derived linear velocity estimates and PSD corrections give a good fit for the duration of the included station position time series, magnitudinal and directional inconsistencies in between regional station velocity estimates may be observed. Not all velocity estimates (especially on Peninsular Malaysia) represent pure inter-seismic motions as is the case with well-established stations in the ITRF2014 that also have long position time series before the occurrence of great $(\mathrm{Mw}>8.0)$ earthquake events. Therefore, also no attempt was made to use the MGRF2020 station velocities on Malaysia to re-define the Sundaland plate motion in IGS14/ITRF2014.

Acknowledgements: We would like to record our gratitude to the Ministry of Energy and Natural Resources (KeTSA) Malaysia for the financial support given during the implementation of the Marine Geodetic Infrastructures in Malaysian Waters (MyMarineGI) Project (20192020).Part of the research work was funded by grants from the Dutch NWO User Support Programme Space Research (2007-2018).

\section{References}

Altamimi Z., Billard P. and Boucher C., ITRF2000, 2002, A new release of the International Terrestrial Reference Frame for earth science applications, JGR Vol. 107, No.B10, 2214.

Altamimi Z., Sillard P., Boucher C., 2006, CATREF Software Combination and Analysis of Terrestrial Reference Frames, IGN, France.

Altamimi Z., Collilieux X. and Metivier L., 2011, ITRF2008: An Improved Solution of The International Terrestrial Reference Frame, Journal of Geodesy, 85, 457-473.

Altamimi Z. Rebischung P., Melvier P. and Collilieux X., 2016, ITRF2014: A new release of the International Terrestrial Reference Frame, modelling non-linear station motions, JGR, Vo. 121 , Issue 8.

Bevis M., Bedford J. and Caccamise D.J., 2020, The Art and Science of Trajectory Modelling, in Geodetic Time Series Analysis in Earth Sciences, Springer Geophysics, Berlin.

Blick G., Crook C., Grant D., and Beavan J., 2006, Implementation of a Semi-Dynamic Datum for New Zealand, International Associ- 
ation of Geodesy Symposia, Vol. 128, A Window on the Future of Geodesy, Proceedings of the International Association of Geodesy, IAG General Assembly Sapporo, Japan June 30 - July 11, 2003.

Bos M.S., Montillet J.P., Williams S.D.P. and Fernandes R.M.S., 2020, Introduction to Geodetic Time Series Analysis, in Geodetic Time Series Analysis in Earth Sciences, Springer Geophysics, Berlin.

Chen K.H., Chuang R.Y. and Ching K.E., 2020, Realization approach of non-linear post-seismic deformation model for Taiwan semi-kinematic reference frame, Earth, Planets and Space (2020) 72:75.

Ching K.E. and Chen K.H, 2015, Tectonic Effect for Establishing a Semi-Dynamic Datum in Southwest Taiwan, Earths, Planets and Space, 67:207.

DSMM, 2011, Country Report of Malaysia, High Level Forum on Global Geospatial Management Information, Seoul, Korea.

DSMM, 2020, The conduct of airborne gravity and magnetic survey over selected area near the international maritime boundary offshore of Peninsular Malaysia, MAGIC Project-Phase IV (2019-2020), Internal Report, Geodetic Division, Department of Survey and Mapping Malaysia.

DSMM, 2020, The development of time-dependent transformation parameters between GDM2000 and ITRF2014, MAGIC ProjectPhase IV (2019-2020), Internal Report, Geodetic Division, Department of Survey and Mapping Malaysia.

FIG, 2014, Reference Frame in Practice Manual, Commission 5, Working Group 5.2.

Freymueller J., 2017, Geodynamics, Springer Handbook of Global Navigation Satellite System, Springer International Publishing.

Geocentric Datum of Australia 2020, 2018, Technical Manual, Version 1.1.1, Intergovernmental Committee on Surveying and Mapping, Australia.

Gill J., Shariff N.S., Omar K. and Amin Z.M., 2015, Tectonics motions of Malaysia: Analysis from years 2001-2013, IGG Conference, Kuala Lumpur.

Jakeli C. and Montenbruck O., 2017, Time and Reference Systems, Springer Handbook of Global Navigation Satellite System, Springer International Publishing.

Jamil H., Mohamed A. and Chang D., 2010, The Malaysia Real-Time Kinematic GNSS Network (MyRTKNet) in 2010 and Beyond, FIG Congress, Sydney.

Jamil H., Kadir M., Forsberg R., Olesen A., Isa M.N., Rasidi S., Mohamed A., Chihat Z., Nielsen E., Majid F., Talib K. and Aman S., 2017, Airborne Geoid Mapping of Land and Sea Areas of East Malaysia, Journal of Geodetic Science, DE GGRUYTER OPEN.

Kadir M., Ses S., Omar K., Desa G., Hisam A., Taib K., Hua T.C., Mohamed A., Hua C.L., Salleh R. and Nordin S., 2003, Geocentric Datum for Malaysia: Implementation and Implications, Seminar on GDM2000, Kuala Lumpur.

Mao A., Harrison G.A. and Dixon T.H., 1999, Noise in GPS Coordinate Time Series, Journal of Geophysics Research, Vol. 104, No. B2, page 2797-2816.

Metivier L., Collilieux X., Lercier D., Altamimi Z., and Beauducel F., 2014, Global coseismic deformations, GNSS time series analysis, and earthquake scaling laws, JGR Solod Earth, Volume 119, Issue 12.

Metivier L., Altamimi Z. and Rouby H., 2020, Past and present ITRF solutions from geophysical perspectives, ScienceDirect, Advances in Space Research 65(2020) 2711-2722.
Mohamed, A., Rasidi S., Chihat Z., Kadir M., Majid F., Talib K. and Aman S., 2018, Geoid Based Height Datum for East Malaysia, The Surveyor, RISM.

Mustafar M.A, Simons W.J.F., Tongkul F., Satirapod C., Omar K. and Pieter N.A.M., 2017, Quantifying Deformation in North Borneo with GPS, Journal of Geodesy.

Poutanen M and Hakli P., 2018, Future of National Reference Frames - from static to kinematic?, Geodesy and Cartography, Polish Academy of Sciences, Vol. 67, No. 1, pp. 117-129.

Qiu Q., Moore J.D.P., Barbot S., Feng L. and Hill M. H., 2018, Transient rheology of the Sumatran mantle wedge revealed by a decade of great earthquakes, NATURE COMMUNICATIONS, (2018) 9:995.

Rasidi S., 2016, Current status of Geocentric Datum of Malaysia 2000 (GDM2000), JUPEM.

Rabah M., Elmewafey M. and Farahan M.H., 2016, Datum Maintenance of the Main Egyptian Geodetic Control Networks by Utilizing Precise Point Positioning “PPP” Technique, NRIAG Journal of Astronomy and Geophysics 5.

Rebischung P. and Schmid R., 2016, IGS14/igs14.atx: A New Framework for the IGS Products. AGU Fall Meeting, San Francisco, CA.

Ronen H. and Even-Tzur G., 2017, Kinematic Datum Based on the ITRF as a Precise, Accurate, and Lasting TRF for Israel, Journal of Surveying Engineering, ASCE.

Sabadini R. and Vermeersen B., 2004, Post-Seismic Deformation, Chapter 8, Global Dynamics of the Earth, Springer Science.

Simons W.J.F., Socquet A., Vigny C., Ambrosius B.A.C., Abu S., Promthong C., Subarya C., Sarsito D.A., Matheussen S., Morgan P. and Spakman W., 2007, A Decade of GPS in Southeast Asia: Resolving Sundaland Motion and Boundaries, Journal of Geophysical Research, Vol. 112.

Simons W. J. F., Naeije M. C., Brown B. E., Niemnil S., Pradit S., Thongtham N., Mustafar M. A., Towatana P., Darnsawasdi R., Yucharoen M., and Visser P. N. A. M., 2019, Vertical motion of Phuket Island (1994-2018) due to the Sumatra-Andaman mega-thrust earthquake cycle: impact on sea-level and consequences for coral reefs. Marine Geology, 414, 92-102.

Stanaway R. and Roberts C., 2013, A high precision deformation Model to support geodetic datum modernisation in Australia, IAG.

Tanaka Y., Saita H., Sugawara J., Iwata K., Toyoda, T., Hirai H., Kawaguchi T., Matsuzaka S., Hatanaka Y., Tobita M., Kuroishi Y., and Imakiire T., 2007, Efficient Maintenance of the Japanse Geodetic Datum 2000 Using Crustal Deformation Models - PatchJGD \& Semi-Dynamic Datum, Bul. Geog. Surv. Inst., Vol.54 March.

U.S. Geological Survey, 2019, Significant Earthquakes Archive, http://earthquake.usgs.gov/earthquakes/eqinthenews.

Vigny C., Simons W.J.F., Abu S., Bamphenyu R., Satirapod C., Choosakul N., Subarya C., Socquet A., Omar K., Abidin H.Z., Ambrosius B.A.C., 2005. Insight into the 2004 SumatraAndaman earthquake from GPS measurements in Southeast Asia, Nature 436, 201-206.

Wan Aris W.A., 2018, Spatio-Temporal Crustal Deformation Model of Sundaland In Malaysia using Global Positioning System, PhD Thesis, Universiti Teknologi Malaysia (UTM).

Wright T.J., 2015, The Earthquake Deformation Cycle and Seismic Hazard in the Continents, The 2015 Bullerwell Lecture, COMET, School of Earth and Environment, University of Leeds, UK. 
Yadav R.K., Kundu B., Gahalaut K., Catherine J., Gahalaut V.K., Ambikapthy A. and Naidu M.S., 2013, Co-seismic offsets due to the 11 April 2012 Indian Ocean earthquakes (Mw 8.6 and 8.2) derived from GPS measurements, GEOPHYSICAL RESEARCH LETTERS, VOL. 40, 3389-3393. 